\title{
The South Asian Monsoon Circulation in Moist Isentropic Coordinates $\mathscr{O}$
}

\author{
T. P. SABIN \\ Centre for Climate Change Research, Indian Institute of Tropical Meteorology, Pune, India, and Center for \\ Prototype Climate Modeling, New York University, Abu Dhabi, United Arab Emirates
}

OLIVIER M. PAUluis

Center for Atmosphere Ocean Science, Courant Institute of Mathematical Sciences, New York University, New York, New York, and Center for Prototype Climate Modeling, New York University, Abu Dhabi, United Arab Emirates

(Manuscript received 21 August 2019, in final form 27 March 2020)

\begin{abstract}
The atmospheric circulation during the South Asian summer monsoon season is analyzed in moist isentropic coordinates. The horizontal mass transport is sorted in terms of its equivalent potential temperature and is separated into the upper- and lower-tropospheric contributions. This technique makes it possible to trace the transport of air parcels over long distances, identify regions of convective motion in the tropics, and assess the impacts of diabatic processes. The goal here is to assess the thermodynamic characteristics of the atmospheric overturning associated with the South Asian monsoon and to connect this thermodynamic structure to horizontal transport. The monsoon is associated with a low-level inflow of warm and moist air, compensated by an upper-tropospheric outflow at high potential temperature. The South Asian monsoon differs, however, from other monsoonal systems in two important ways. First, the ascending air exhibits an unusually high equivalent potential temperature, which results in global lifting of the tropopause during the boreal summer. Second, on a seasonal basis the main monsoon regions appear to be shielded from dry air intrusion from the extratropical regions.
\end{abstract}

\section{Introduction}

The Asian summer monsoon is a spectacular manifestation of the seasonal reversal of the general circulation of the atmosphere, driven by the differential solar heating between the two hemispheres and by the thermal contrast between land and ocean during the boreal summer. The circulation undergoes an abrupt change by the end of May, with an elongated warm belt extending from the Arabian Desert to southwestern China (Cadet 1979; Choudhury and Krishnan 2011). The vicinity of oceans and subtropical deserts and complex interactions between air masses with different thermodynamic properties make the South Asian monsoon a complex problem in fluid dynamics. The Himalayan and Hindu Kush mountains partially protect the warm and moist

\footnotetext{
Supplemental information related to this paper is available at the Journals Online website: https://doi.org/10.1175/JCLI-D-190637.s1.
}

Corresponding author: T. P. Sabin, sabin@tropmet.res.in tropical air from the cold and dry midlatitude air (Boos and Kuang 2010, 2013). However, during the weak phase of the monsoon, dry air intrudes toward the monsoon region through the Arabian Sea and northwestern India by advection and wave interaction (Krishnan et al. 2009; Krishnamurti et al. 2010; Fadnavis and Chattopadhyay 2017). Such dry intrusion limits the moisture content of the low-level inflow and decreases convective instability by reducing the parcel buoyancy and enhancing radiative thermal inversion (Mapes and Zuidema 1996; Brown and Zhang 1997; Chou and Neelin 2003; Krishnan et al. 2009; Sabin et al. 2013). This can inhibit the further development of organized convection over the core monsoon region. Hence, understanding the origin, structure, and complex interaction of the different air masses pertaining to the South Asian summer monsoon in an efficient way is of profound scientific necessity.

The strong coupling between continental-scale circulation and convection makes the South Asian summer monsoon unique compared to other regional weather phenomena. The orography and the strength of deep, 
moist monsoon convection have significant roles in blocking cold, dry extratropical air from entering the monsoon domain. Few studies have endeavored to investigate the vertical thermal structure during the monsoon season (Krishnamurti et al. 2010; Krishnan et al. 2009). Most existing studies have concentrated on constructing the swath of parcel trajectories of dry air descending to Indian landmass during onset or break phase of monsoon (Krishnamurti et al. 2010; Parker et al. 2016). Using profiles from twice-daily balloon sonde and reanalysis data, Boos and Kuang (2010) showed an upper-tropospheric potential temperature maximum that spans the Indian subcontinent, in line with the boundary layer moist static energy maxima. This convective quasi-equilibrium structure emphasizes the strength of the diabatic effects of moist convection and the strong insulation between lowentropy extratropical air and high-entropy tropical air (Nie et al. 2010).

The central role played by thermal forcing motivates the recasting of monsoonal circulation in thermodynamic coordinates. In atmospheric science, the use of potential temperature as a vertical coordinate dates back to the 1930s with the introduction of isentropic analysis (Rossby et al. 1937). Tracking an air parcel with respect to its potential temperature $(\theta)$ will simplify the circulation into a single overturning cell in each hemisphere, with an upper-level poleward flow and a balanced surface return flow instead of the three-cell structure in Eulerian mean circulation (Townsend and Johnson 1985; Johnson 1989; Held and Schneider 1999). Potential temperature, however, is not conserved in the presence of phase transitions, which limits its usefulness for studying tropical circulation. In contrast, equivalent potential temperature $\left(\theta_{e}\right)$ is an adiabatic invariant even when phase transition is taken into account. In recent years, it has been used as a thermodynamic coordinate to study a broad range of atmospheric flows (Czaja and Marshall 2006; Pauluis et al. 2008, 2010; Pauluis and Mrowiec 2013; Wu and Pauluis 2014; Mrowiec et al. 2015; Laliberté et al. 2015; Chen et al. 2018; Wu et al. 2019). The primary purpose of this paper is to describe the South Asian summer monsoon using equivalent potential temperature as a coordinate system and to connect the zonal mean of meridional overturning circulation to its local manifestation over South Asia. In doing so, we aim to better elucidate the connections between large-scale atmospheric flow, convection, and energy and moisture transport.

\section{Model and data used}

We used the High-Resolution Atmospheric Model (HiRAM) developed at the Geophysical Fluid Dynamics
Laboratory (NOAA/GFDL). The present version of HiRAM includes a finite-volume dynamical core (Lin 2004) on a cubed-sphere (Putman and Lin 2007) grid with a modified shallow convection scheme (Bretherton et al. 2004) and a six-class bulk cloud microphysics scheme to represent the convection and cloud processes (Anderson et al. 2004). The model has a horizontal grid spacing of approximately $25 \mathrm{~km}$ with 32 vertical levels. The cubed-sphere grid provides excellent grid uniformity with a high degree of efficiency and more accurate numerical solutions of partial differential equations on the sphere, especially by eliminating the singularity at the poles (Ronchi et al. 1996). The dynamical core provides considerable numerical accuracy along with improving the model's scalability. AMIP-type simulations were carried out with prescribed sea surface temperature and sea ice for 30 years, 1976-2005 (we used the 25 years from 1981 to 2005 for diagnostics). The parameterization scheme used in HiRAM is not meant to represent the effect of deep convection explicitly (Bretherton et al. 2004). Instead, the model resolves deep convection at the grid scale, so that outside the boundary layer, the upward transport of energy and moisture is primarily due to resolved atmospheric motions rather than the model parameterization.

Previous studies have shown that HiRAM has an excellent capability to realistically reproduce tropical storms over different ocean basins (Zhao et al. 2009). In addition, HiRAM exhibits excellent performance in simulating monsoon low-pressure systems (Sandeep et al. 2018), which is an integral part of seasonal mean precipitation over the central and northern Western Ghats, which contribute $55 \%$ to $70 \%$ of total seasonal precipitation (Krishnamurthy and Ajayamohan 2010). Figure 1 compares the precipitation and circulation at $850 \mathrm{hPa}$ simulated by HiRAM with data from the TRMM (Tropical Rainfall Measuring Mission; Huffman et al. 2007) and MERRA (Modern-Era Retrospective Analysis for Research and Applications; Rienecker et al. 2011) reanalysis, respectively. It confirms the ability of the model to accurately reproduce the global distribution of rainfall along with finescale regional features over South Asia. Figure 2 presents a more focused comparison for the South Asian monsoon region with greater detail of the low-level westerly monsoon circulation, which brings moisture from the oceanic region; this also shows that HiRAM compares well with the MERRA reanalysis in the area of interest. Model bias in precipitation and circulation is shown in Figs. S1a and $\mathrm{S} 1 \mathrm{~b}$ in the online supplemental material. Figure S1c shows the Taylor diagram displaying the statistical comparison of mean June-September (JJAS) precipitation 
a) HiRAM

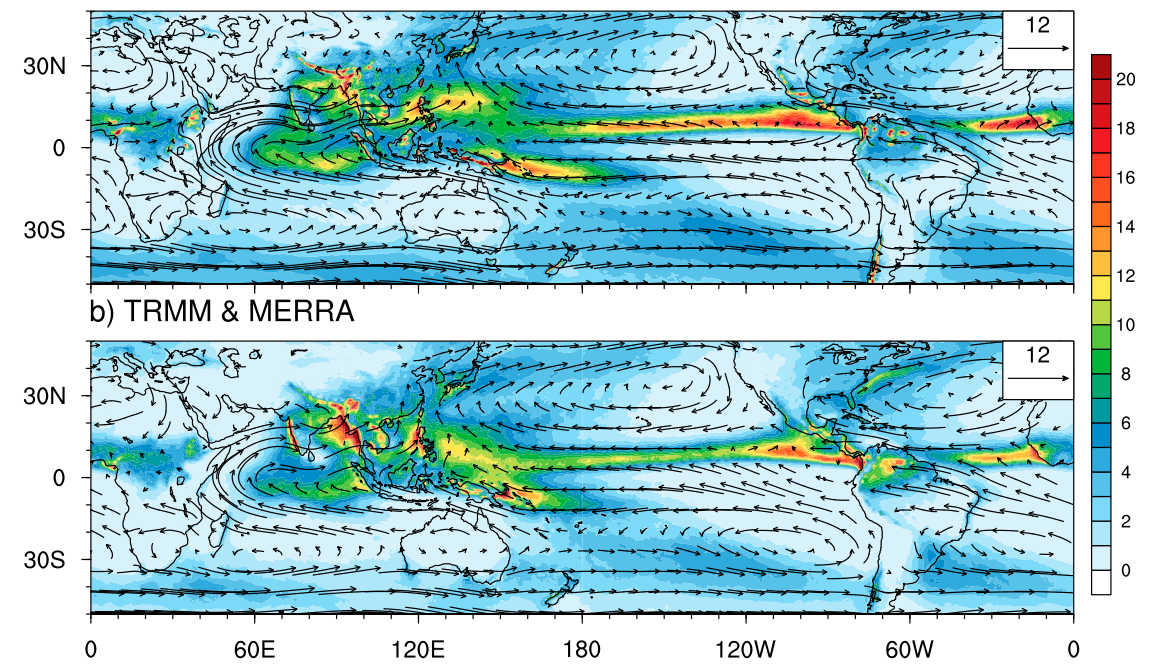

FIG. 1. Spatial maps of seasonal (JJAS) mean precipitation $\left(\mathrm{mm} \mathrm{day}^{-1}\right)$ and 850 -hPa circulation $\left(\mathrm{m} \mathrm{s}^{-1}\right.$ ) from (a) HiRAM simulation and (b) TRMM and MERRA reanalysis. The precipitation climatology of TRMM is from 1998 to 2017, whereas HiRAM and MERRA use the average for the 1981-2005 period.

between HiRAM and other AMIP simulation as part of CMIP5 experiments. Even though the model has a dry bias over the Western Ghats, over the monsoon trough region, precipitation is well comparable with the TRMM observations (Fig. S1d). The strong cyclonic turning over the Bay of Bengal and even finer details such as dry air intrusion from the desert region are reproduced well in the simulation. The maximum wind speed in the core of the low-level jet is $18 \mathrm{~m} \mathrm{~s}^{-1}$, which is slightly overestimated. The zonally averaged $\left(60^{\circ}-90^{\circ} \mathrm{E}\right)$ latitudinal variation of zonal wind at $850 \mathrm{hPa}$ over the monsoon region shows high correlation (0.99) with the reanalysis data (Fig. 2c). The upper-level circulation pattern also compares well with the MERRA reanalysis data (figure not shown). Together, these reinforce our confidence that this model configuration can accurately reproduce the thermodynamic structure of the monsoonal circulation.

\section{Isentropic circulation during the northern summer}

\section{a. Meridional overturning}

Adiabatic invariants such as entropy, equivalent potential temperature, and liquid water potential temperature are thermodynamic variables that are conserved for reversible adiabatic transformations. In contrast with other variables, such as pressure, temperature, or specific humidity, adiabatic variables remain constant during rapid adiabatic expansion or phase transition. Atmospheric scientists have taken advantage of the conservation properties of these variables to study atmospheric flow since the early development of dynamical meteorology (Rossby et al. 1937). Here, following Pauluis et al. (2008), we are interested in characterizing the meridional circulation averaged on dry isentropes, defined as surfaces of constant potential temperature, and on moist isentropes, defined as surfaces of constant equivalent potential temperature. The dry and moist isentropic streamfunctions for the meridional circulation can be computed as follows:

$$
\begin{gathered}
\boldsymbol{\Psi}_{\theta}\left(\theta_{0}, \phi\right)=\int_{0}^{2 \pi} \int_{0}^{p_{s}} \frac{a \cos \phi}{g} v H\left[\theta_{0}-\theta(\lambda, \phi, p, t)\right] d p d \lambda \\
\boldsymbol{\Psi}_{\theta_{e 0}}\left(\theta_{e 0}, \phi\right)=\int_{0}^{2 \pi} \int_{0}^{p_{s}} \frac{a \cos \phi}{g} v H\left[\theta_{e 0}-\theta_{e}(\lambda, \phi, p, t)\right] d p d \lambda .
\end{gathered}
$$

Here, $\phi$ is the latitude; $\lambda$ is the longitude; $p$ is the pressure; $p_{s}$ is the surface pressure; $a$ is the radius of Earth; $g$ is the acceleration due to gravity; $H$ is the Heaviside function; $\nu$ is the meridional velocity; $\theta$ and $\theta_{e}$ are the potential temperature and equivalent potential temperature, respectively; and $\theta_{0}$ and $\theta_{e 0}$ are the arbitrary reference value of $\theta$ and $\theta_{e}$, respectively. Here, we use the equivalent potential temperature as defined by Emanuel (1994). Figure 3 shows the mean summertime (JJAS) streamfunction on $\theta$ and $\theta_{e}$ surfaces (Figs. 3a,b), which are qualitatively and quantitatively similar to the ones based on reanalysis data demonstrated by Pauluis et al. (2010). In isentropic coordinates, the meridional 
a) HiRAM

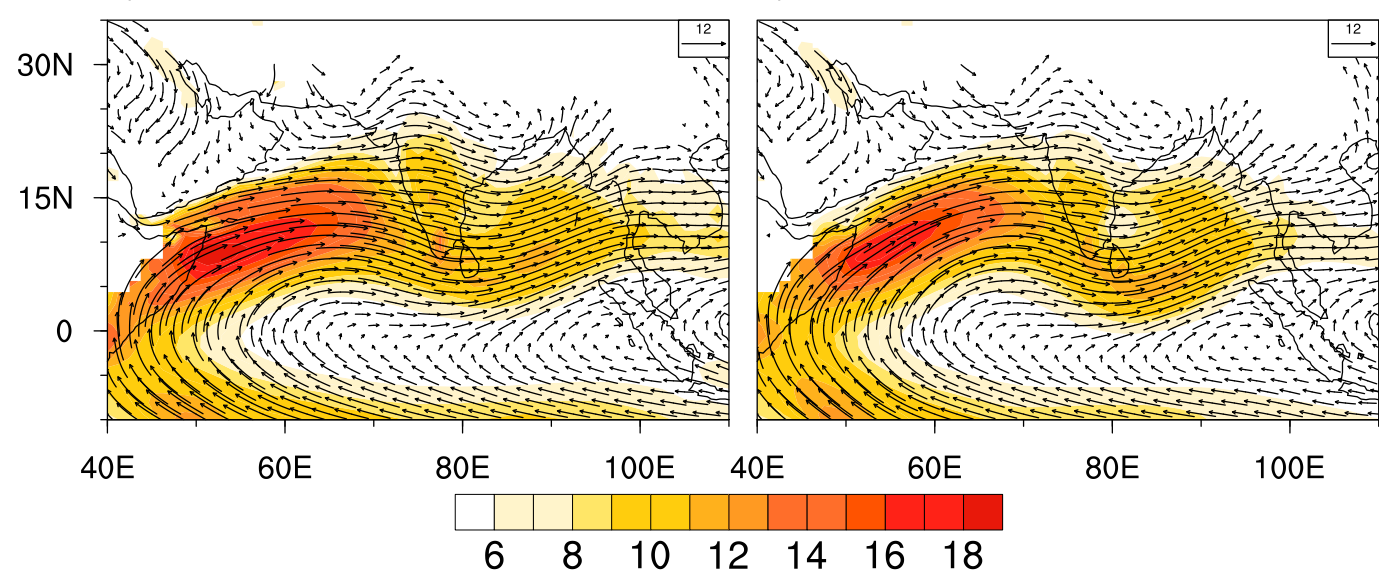

c) Zonal wind at $850 \mathrm{hPa}(60 \mathrm{E}$ to $90 \mathrm{E})$

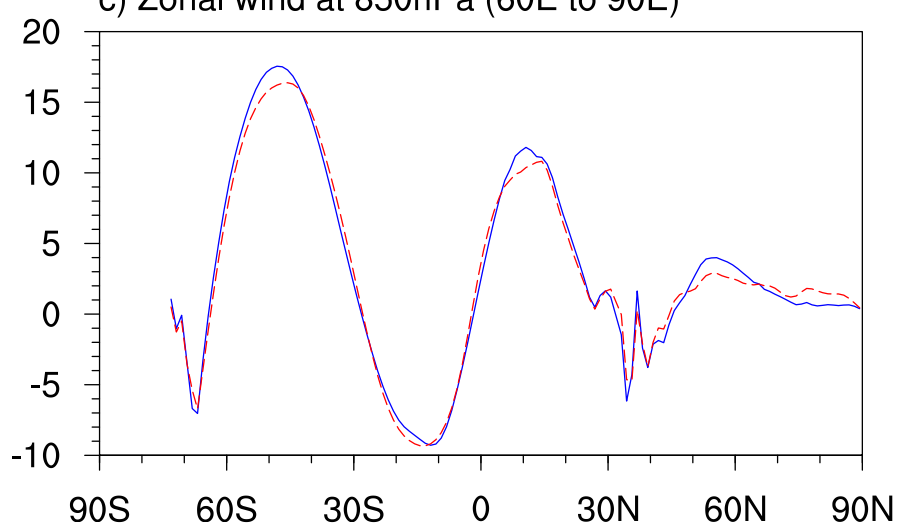

FIG. 2. Low-level circulation at $850 \mathrm{hPa}\left(\mathrm{m} \mathrm{s}^{-1}\right)$ from (a) HiRAM and (b) MERRA for the JJAS season over the monsoon region. Corresponding wind speed is shown in shadings. Here the model data are regridded to MERRA resolution for better comparison. (c) Latitudinal variation of zonally averaged $\left(60^{\circ}-90^{\circ} \mathrm{E}\right)$ zonal winds at $850 \mathrm{hPa}$ from HiRAM (blue) and MERRA (red) for JJAS season.

circulation appears as an equator-to-pole direct circulation, with poleward transport of air with high equivalent potential temperature and a return flow of air at lower equivalent potential temperature. The circulation thus corresponds to a poleward energy transport necessary to redistribute the excess radiative energy absorbed in the equatorial region to higher latitudes.

During the Northern Hemisphere summer, the circulation on dry isentropes is dominated by the crossequatorial Hadley cell, with a mass transport of approximately 200 Sverdrups (Sv; $1 \mathrm{~Sv} \equiv 10^{6} \mathrm{~m}^{3} \mathrm{~s}^{-1}$ ). The Hadley circulation is characterized by a flow from the Southern to the Northern Hemisphere with a potential temperature between 290 and $310 \mathrm{~K}$, characteristic of the lower troposphere, and a return flow at a potential temperature between 330 and $360 \mathrm{~K}$, indicative of the upper troposphere. The ascending branch of the circulation takes place between the equator and $15^{\circ} \mathrm{N}$. The ascent in $\theta$ coordinates corresponds to an increase in potential temperature associated with the latent heat release over the precipitating regions. The downward branch of the circulation occurs in a vast region extending south of the equator (Webster et al. 1998; Gadgil 2003, 2018). The dry isentropic circulation extends all the way to the South Pole in the Southern Hemisphere. In the Northern Hemisphere, however, the circulation on dry isentropes is extremely weak.

As discussed in Pauluis et al. $(2008,2010)$, the circulations on moist isentropes differ from the circulation on dry isentropes in three substantial ways: 1) the crossequatorial Hadley circulation is substantially weaker, 2) the mass transport peaks in the extratropics, and 3) there is a significant circulation in the Northern Hemisphere. These differences are tied to the latent heat transport. When water vapor is transported in the opposite direction to the total energy transport, as is the case for the cross-equatorial Hadley circulation, the circulation on moist isentropes is weaker than on dry isentropes. Conversely, in regions where the moisture transport is in the same direction as the energy transport, that is, in the 

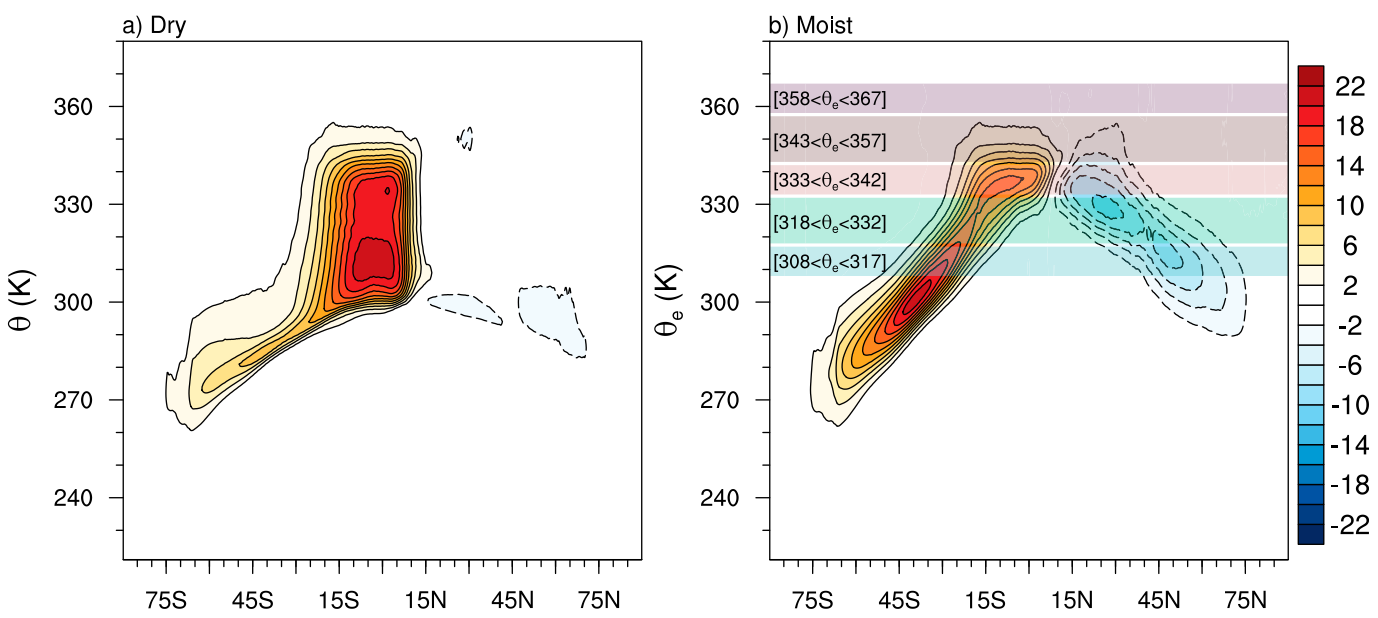

FIG. 3. Global circulation in isentropic coordinates from HiRAM simulation for JJAS season. Streamfunction on (a) dry and (b) moist isentropes shows the equatorward flow at low $\theta / \theta_{e}$ and poleward flow at high $\theta / \theta_{e}$ in the Southern (positive) and Northern (negative) Hemispheres. The different moist ventilation range used for isentropic analysis is highlighted in horizontal shadings.

subtropics and midlatitudes, the circulation on moist isentropes is stronger. The circulation on dry isentropes may lead to the false impression that there is little interaction between the tropics and extratropics in the Northern Hemisphere. This notion is, however, disproved by the circulation on moist isentropes, which exhibits a robust flow in the Northern Hemisphere. This flow corresponds to the air, moisture, and energy exchange due to the intrusion of dry extratropical air masses into the subtropical and the export of warm, moist tropical air into the storm tracks. Thus, mass exchange occurs through a combination of stationary and transient eddies and results in seamless energy transport between the tropics and extratropics (Shaw and Pauluis 2012). The equivalent potential temperature of the inflow into the equatorial regions is typically $\theta_{e}<332 \mathrm{~K}$, while the outflow occurs at higher values of $\theta_{e}>343 \mathrm{~K}$. While the inflow is confined to the lower troposphere, the outflow occurs both as a return flow of the crossequatorial circulation in the upper troposphere and as a low-level subtropical export of warm, moist air in the Northern Hemisphere.

The meridional circulation offers only a broad view of the atmospheric circulation and overlooks some of the regional characteristics. To remedy this, we will analyze the horizontal transport of air parcels in terms of their equivalent potential temperature. We defined the specific five ranges based on the best possible way of representing the different range of air masses connected with monsoon and its subseasonal features. As shown in Fig. 3b, air parcels moving in and out of the tropical regions $\left(30^{\circ} \mathrm{S}-30^{\circ} \mathrm{N}\right)$ can be sorted out into five different $\theta_{e}$ categories:
1) extratropical air mass $\left(308<\theta_{e}<317 \mathrm{~K}\right)$, which is mostly confined outside of the tropics;

2) subtropical dry air mass $\left(318<\theta_{e}<332 \mathrm{~K}\right)$, characteristic of the primary inflow into the tropical regions;

3) tropical moist air mass $\left(333<\theta_{e}<342 \mathrm{~K}\right)$, which is typical of the air exported to the extratropics;

4) Asian monsoon air mass $\left(343<\theta_{e}<357 \mathrm{~K}\right)$, associated with the upper branch of the Hadley circulation; and

5) extremely moist air mass $\left(358<\theta_{e}<367 \mathrm{~K}\right)$, which is typically higher than the potential temperature at the tropopause.

In the tropics, vertical profiles of $\theta_{e}$ often exhibit a midtropospheric minimum (Pauluis et al. 2010; Chen et al. 2018). As such, it is not always possible to separate the upper and lower components of the flow based on equivalent potential temperature alone. To address this issue, we separate the isentropic flow into upperand lower-tropospheric contributions, defined as the mass transport occurring at pressures above and below $500 \mathrm{hPa}$, which also qualitatively corresponds to the midtropospheric minimum in equivalent potential temperature. The isentropic thickness denotes the weight of the air column due to the respective $\theta_{e}$ range, which can be interpreted as a measure of the instability of that layer.

\section{b. Lower-tropospheric flow}

The isentropic thickness (shading) and mass transport (arrows) for the different ranges of equivalent potential temperature for the lower troposphere are shown in Fig. 4. The extratropical air mass $\left(308<\theta_{e}<317 \mathrm{~K}\right)$ is 
mostly confined to the extratropics (Fig. 4a). The difference between the summer (Northern) and winter (Southern) hemispheres is noticeable in that low- $\theta_{e}$ air is much farther poleward in the former than the latter. Extratropical air either moves farther poleward, where it ascends into the upper troposphere through the action of baroclinic eddies, or it is advected equatorward, where it will gradually gain energy from its interaction with Earth's surface and will be transformed into subtropical air. Extratropical air is mostly absent from the tropical regions, except for some notable dry air intrusion from the Southern Hemisphere on the eastern side of the Pacific and Atlantic Oceans. These intrusions thus occur on the eastern side of the subtropical anticyclones and regions characterized by relatively low sea surface temperatures.

The subtropical dry air mass $\left(318<\theta_{e}<332 \mathrm{~K}\right)$ accounts for most of the low-level air over the subtropical anticyclones over the Pacific and Atlantic Oceans. It also represents most of the air over the Sahara Desert and most of the Somali jet on the southern side of the equator (Fig. 4b). It is, however, noticeably absent over South Asia. Subtropical air is exported poleward toward the storm tracks and equatorward toward the intertropical convergence zone (ITCZ). In most of the equatorial regions, the subtropical air masses are transported westward by the trade winds, except over the Arabian Sea, where there is an eastward transport by the Somali jet.

The tropical moist air mass $\left(333<\theta_{e}<342 \mathrm{~K}\right)$ is found over most of the convective regions, including the African monsoon, Bay of Bengal, warm pool over the western Pacific, and the ITCZ in the east Pacific and Atlantic Oceans (Fig. 4c). The low-level flow of moist tropical air is typically into the regions of deep convection, where warm, moist air ascends into the upper troposphere. There are only two regions of noticeable poleward export of moist tropical air: along the east coast of China and over Mexico. Air with a high value of $\theta_{e}\left(343<\theta_{e}<357 \mathrm{~K}\right)$, which we named the Asian monsoon air mass, can be found over northern India, the South China Sea, and to a lesser extent over the east Pacific and western Africa (Fig. 4d). This ventilation (the usage of ventilation here simply denotes the bulk of air mass, computed by sorting the air parcels in infinite $\theta_{e}$ bins and then summed up to categories to respective equivalent potential temperature range) of uncharacteristically moist air identifies deep convection based on the isentropic thickness, and the strong mass transport clearly represents the low-level jet that provides moisture for the intense convection over the Indo-Gangetic Plain. Finally, air parcels with extremely high $\theta_{e}>358 \mathrm{~K}$ can sometimes be found over the Asian monsoon, west Pacific, and the Gulf of Mexico. Over the Indo-Gangetic Plain, this extremely moist air mass occurs due to the intense deep convection associated with synoptic scale disturbances (Fig. 4e).

The South Asian monsoon appears as an extensive region characterized by a lack of dry subtropical air (Fig. 4b). Subtropical dry air intrudes over the Arabian Sea and creates an inversion layer extending from the lowland of eastern Africa to the Arabian Sea. This layer inhibits the development of thick clouds, as noted from the observations during the International Indian Ocean Expedition (Bunker 1965). At a subseasonal scale, incursions of desert air toward central India lead to the formation of a blocking high over western Asia and advect very dry air toward central India (Krishnamurti et al. 2010). Strong mixing of dry and moist air in the two narrow bands of subtropical dry air and tropical moist air likewise occur in subseasonal scale (active-break phase). The moisture distribution over the Arabian Sea is stratified during the break phase, while in the active phase, the stratification disappears with the moisture advection toward the Indian subcontinent along with a strong upward transport of water vapor (Ramamurthy et al. 1976), which is further described in section 4 .

\section{c. Upper troposphere}

The distribution of the various air masses in the upper troposphere, which differs substantially from that in the lower troposphere, is shown in Fig. 5. As there is only a small amount of water vapor, there is little difference between identifying upper-tropospheric air parcels in terms of their potential temperature and in terms of equivalent potential temperature. The extratropical air mass $\left(308<\theta_{e}<317 \mathrm{~K}\right)$ can be found over the polar region of the Northern Hemisphere and midlatitudes of the Southern Hemisphere. It is also reaches farther poleward than the distribution of the same air mass at low level. The mass transport is mostly toward the east. There is a weak poleward drift associated with the meridional overturning circulation (see Fig. 3), but it cannot be easily seen in Fig. 5 a.

The subtropical dry air mass $\left(318<\theta_{e}<332 \mathrm{~K}\right)$ has the same equivalent potential temperature as air found in the upper troposphere over the storm tracks. This illustrates the isentropic connection between the low-level dry subtropical region and the extratropics. Notably, the upper troposphere is primarily characterized by the export of dry subtropical air from the subtropical anticyclone regions to the storm tracks, except for the Mediterranean Sea, where one can observe transport of subtropical dry air mass toward northern Africa. 
a) Extratropical air mass

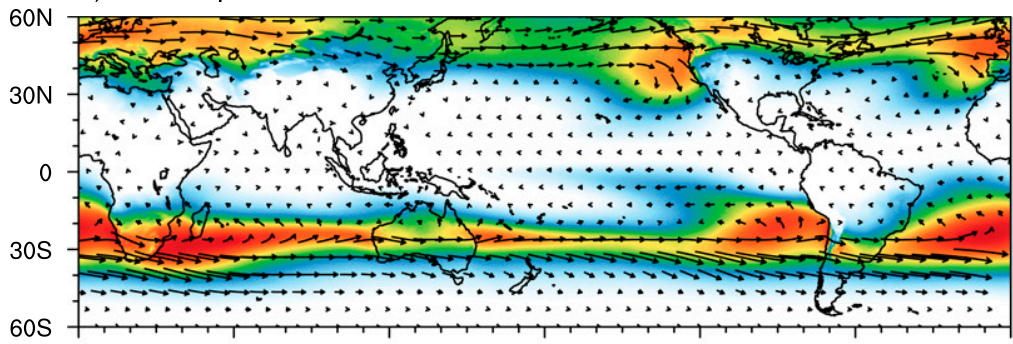

b) Subtropical dry air mass

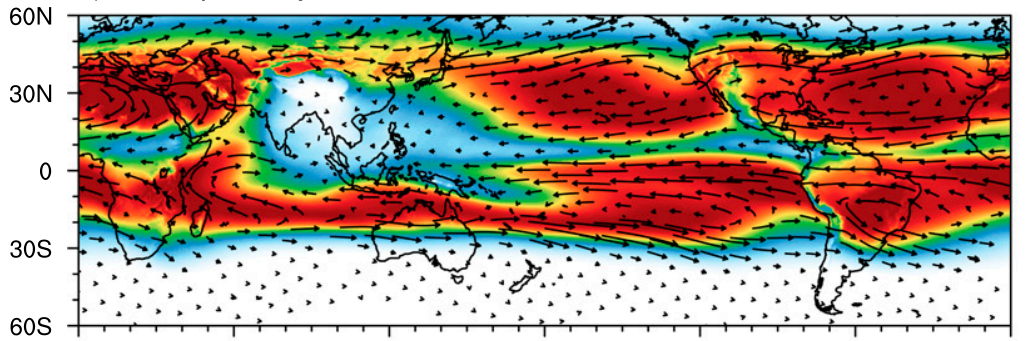

c) Tropical moist air mass

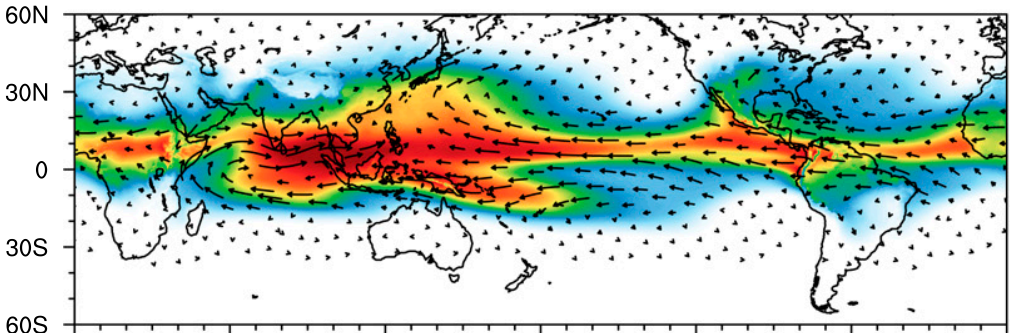

d) Asian monsoon air mass
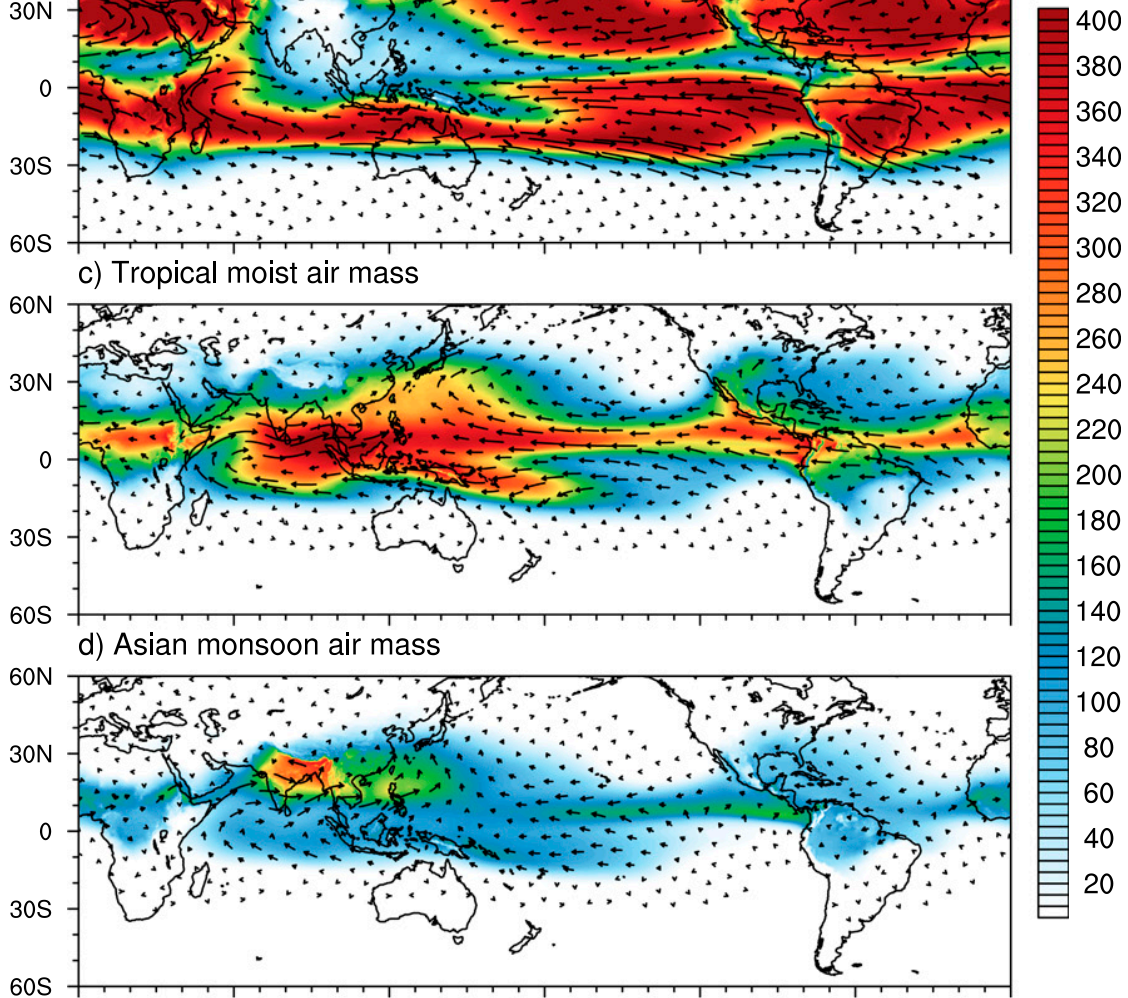

e) Extremely moist air mass

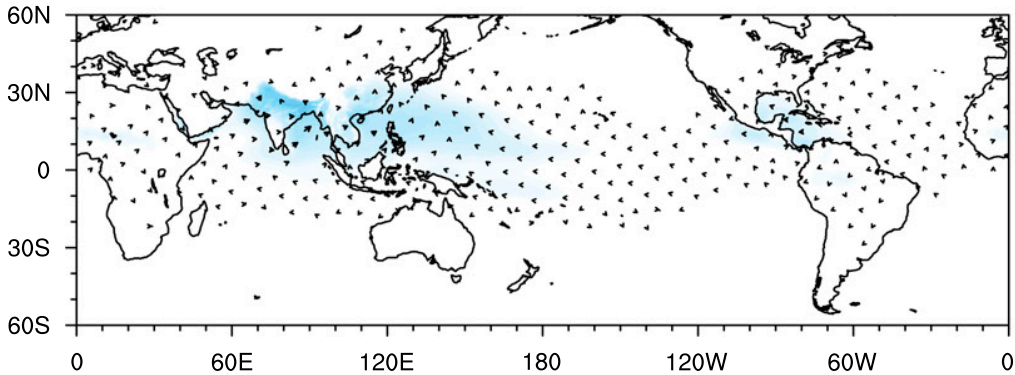

FIG. 4. Isentropic thickness (shading) in hectopascals and mass transport (arrows) for the different moist ventilation range of the tropical atmosphere in the lower troposphere (below $500 \mathrm{hPa}$ ) during JJAS season. (a) Extratropical air mass, (b) subtropical dry air mass, (c) tropical moist air mass, (d) Asian monsoon air mass, and (e) extremely moist air mass. Different moist ventilation rages are categories as per the $\theta_{e}$ range as highlighted in horizontal shadings in Fig. 3. 
a) Extratropical air mass

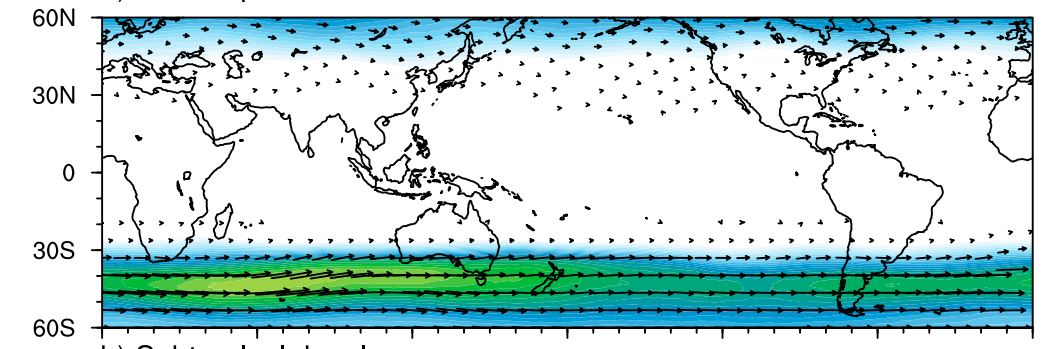

b) Subtropical dry air mass
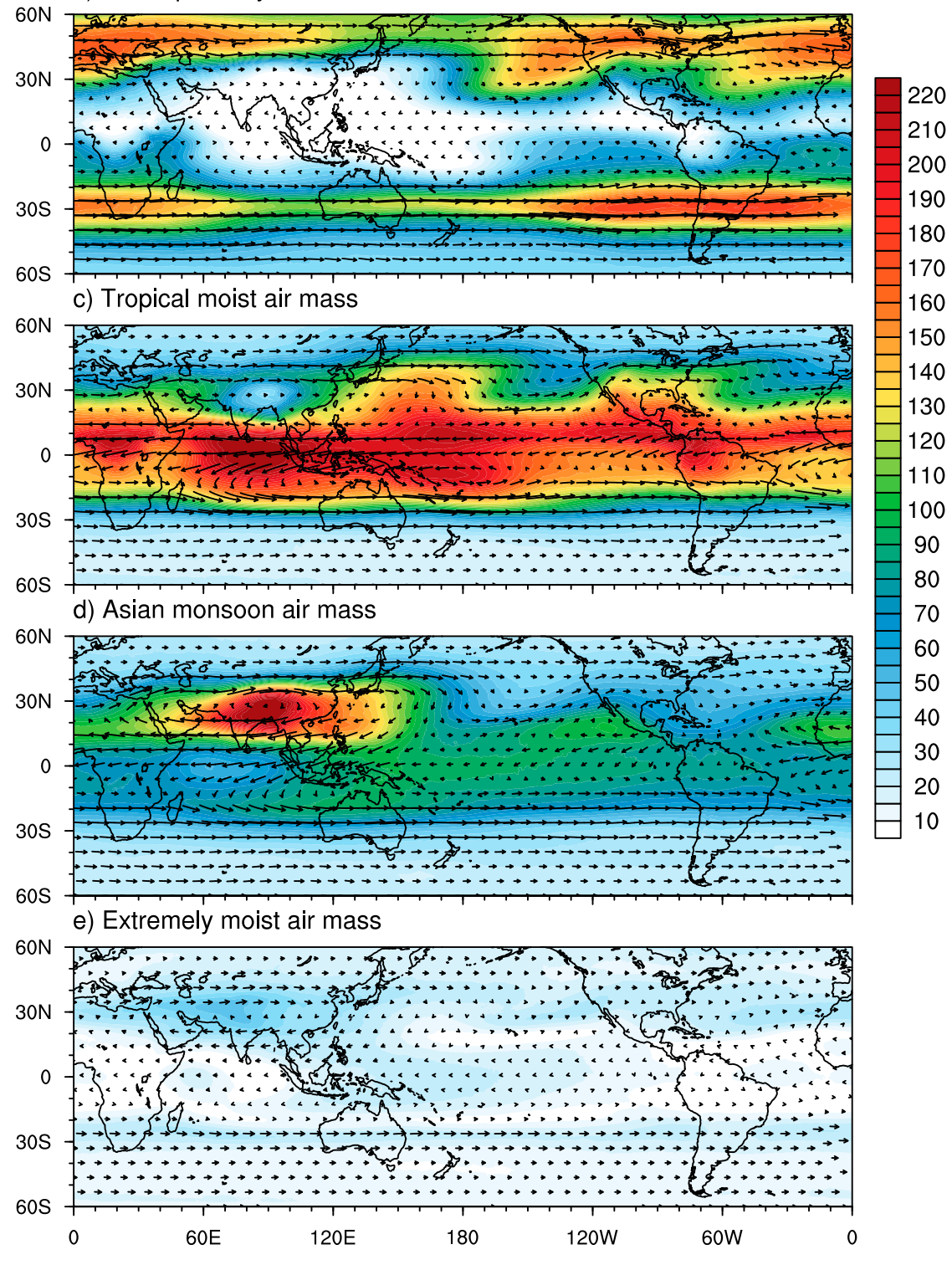

FIG. 5. As in Fig. 4, but for the upper troposphere (above $500 \mathrm{hPa}$ ).

The tropical moist air mass $\left(333<\theta_{e}<342 \mathrm{~K}\right)$ spans the entire tropical belt from $30^{\circ} \mathrm{N}$ to $30^{\circ} \mathrm{S}$, with more northward extension over the west Pacific associated with the upper-level outflow of typhoons and synoptic systems (Fig. 5c). This moist air keeps the upper troposphere high over the equatorial region. This is consistent with the interpretation that the tropical upper troposphere is constantly replenished by warm and 
moist air ascending over regions of deep convection (Sherwood et al. 2010) and the role of Asian monsoon toward this process is clearly visible from this analysis. The mass transport of moist tropical air is dominated by the cross-equatorial return flow of the Hadley circulation from the Northern to the Southern Hemisphere.

The Asian monsoon air mass $\left(343<\theta_{e}<357 \mathrm{~K}\right)$ reveals the anticyclonic circulations over the Tibetan Plateau and thermodynamic centers of heating associated with the monsoon (Fig. 5d). The relatively strong isentropic thickness and divergent mass transport at this range are manifestations of the tropical easterly jet, with maximum transport just south of the Indian subcontinent. This upper-level structure of the circulation depicts the deep and extensive convection that constitutes the upward vertical branch of the Asian summer monsoon. The primary downward branch occurs in a vast region extending toward the south of the Indian Ocean. The same category of equivalent potential temperature forms the bulk of the air mass within the upper-tropospheric anticyclone, which is the descending branch of the monsoon Hadley circulation. The upward diabatic branch of the monsoon circulation is forced by the combined effect of latent energy transport and sensible heating over the Tibetan Plateau and Asia. As pointed out by Johnson (1989), the energy gained through sensible and latent heating in the heat source regions is transported in upper isentropic levels to the heat sink, where warming through subsidence is balanced by the atmospheric cooling from infrared emission. Air with extremely high $\theta_{e}>358 \mathrm{~K}$ is confined over the region dominated by the subtropical storms and intense synoptic system associated with the monsoon (Fig. 5e). This transport of energy in high equivalent potential temperature air has a significant role in lifting the tropopause globally during the Northern Hemisphere summer. Wu and Pauluis (2014) provided a connection between the tropopause and isentropic streamfunction by computing the mass flux of the atmospheric circulation. Many studies tried to understand this over the subtropical or tropical area even in light of global warming ( $\mathrm{Wu}$ and Pauluis 2013, 2014; Shaw and Pauluis 2012; Shaw 2014; Lin et al. 2017). Chen et al. (2018) demonstrated that during the JJAS season the majority of the vertical mass transport is happening over the Asian monsoon region. The presence of high-entropy air in the extremely moist ventilation range of the tropical atmosphere further implies the strength of the convection associated with the Asian monsoon, which is eventually responsible in uplifting the tropical tropopause.

\section{d. Vertical velocity $\left(\omega_{\theta_{e}, \mathrm{Z}}\right)$ at $500 \mathrm{hPa}$ for a given range of equivalent potential temperature}

Following Pauluis and Mrowiec (2013), we computed the isentropic vertical velocity $\left(\omega_{\theta_{e}, Z}\right)$ at $500 \mathrm{hPa}$ for each of our defined moist ventilation ranges of equivalent potential temperature (Fig. 6). This allows us to distinctly identify the characteristic features of different air masses involved in atmospheric overturning circulation. One can clearly visualize the descent over the subtropics from the vertical velocity field associated with the extremely dry range of $\theta_{e}<317 \mathrm{~K}$ (Fig. 6a). Low-energy air with $318<\theta_{e}<332 \mathrm{~K}$ (Fig. 6b) further demonstrates the subsidence over the subtropics and the ascending air over the midlatitude storm tracks. In addition, the large subsidence over the deserts west of the Hindu Kush mountain range is also clearly visible from the positive vertical velocity (subsidence) in this range. The sharp updraft and downdraft over the narrow mountains and valleys are a bit concern; however on a broader scale this may not affect the assessment. Figure 6c shows the vertical velocity as part of the tropical moist air mass in the range $333<\theta_{e}<342 \mathrm{~K}$. The convection over the Indian Ocean, west Pacific, ITCZ of the Pacific and Atlantic, and the shallow convection associated with the African summer monsoon are related to the strong vertical ascent in this moist band. Strong upward motion (Fig. 6c) obviously coincides with regions with a high value of isentropic thickness (Fig. 4c). Air within this range of equivalent potential temperature rises through the convective regions around the global tropics and also within the storm tracks except for the convection associated with the continental-scale precipitation associated with the Asian summer monsoon and deep convection as part of the west Pacific storms. The strong vertical velocity in the moist range $\left(343<\theta_{e}<357 \mathrm{~K}\right)$ is clearly confined over the Indo-Gangetic Plain and west Pacific (Fig. 6d). Air parcels with such a high equivalent potential temperature are typically associated with intense vertical ascent as part of the deep convection over the monsoon trough and the typhoons over the western Pacific.

Ascent of the extremely moist air mass $\left(358<\theta_{e}<\right.$ $367 \mathrm{~K})$ occurs intermittently. In the climatological mean pattern, the ascent of such high-entropy air is only noticeable over northern India (Fig. 6e). However, when shorter windows are evaluated, such as the 1-month average as shown in Fig. 7, several lines of ascending air can be detected over the western and central Pacific and the Gulf of Mexico. These correspond to the tracks of individual tropical storms as simulated by the model. This is consistent with Mrowiec et al. (2016) who demonstrated the eyewall of tropical cyclones is characterized 
a) Extratropical air mass

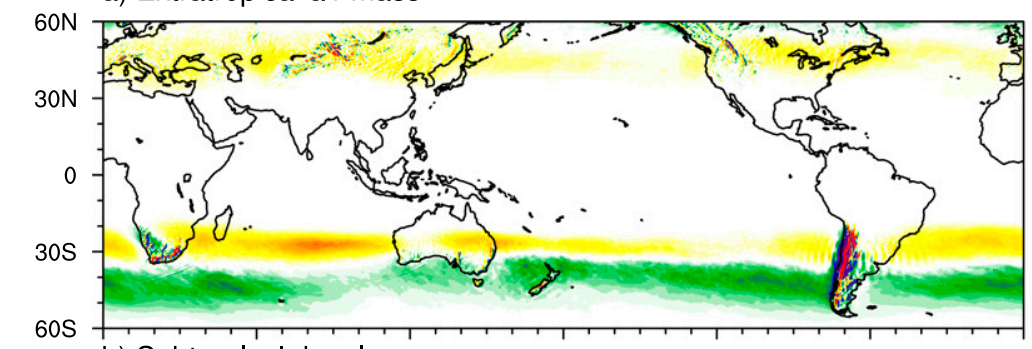

b) Subtropical dry air mass

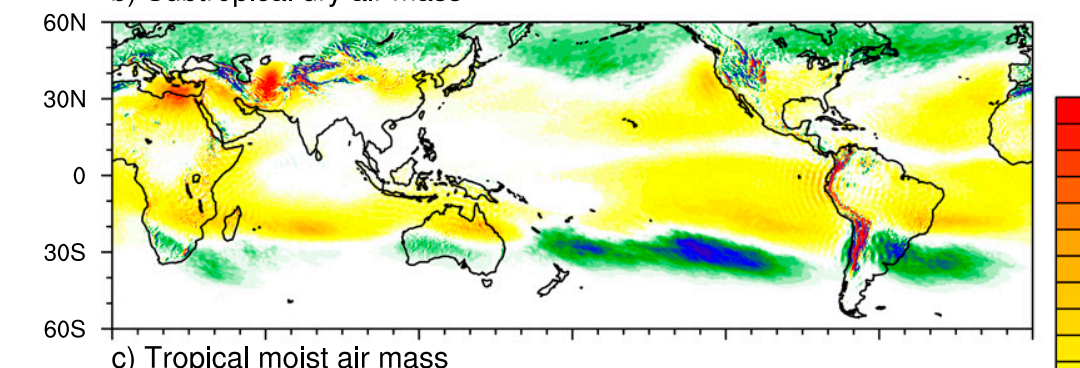

$$
-2
$$
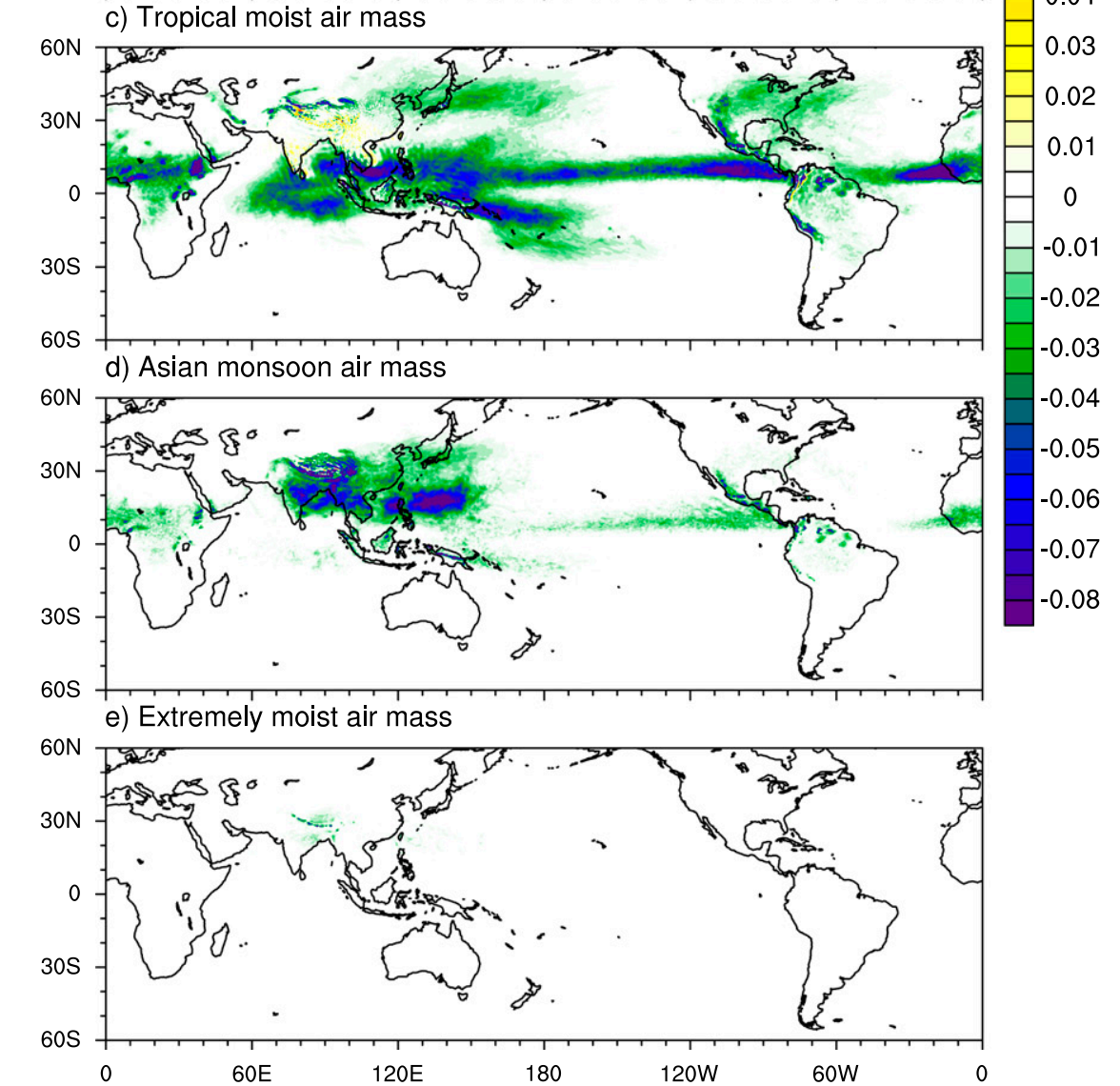

FIG. 6. Isentropic vertical velocity $\left(\omega_{\theta_{e, Z}}\right)$ at $500 \mathrm{hPa}\left(\mathrm{Pa} \mathrm{s}^{-1}\right)$ for respective moist ventilation range as highlighted in Fig. 3.

by the ascent of air parcels with very high equivalent potential temperature. This indicates that the ascent of high-entropy air can be used to readily detect storms and depressions in large-scale atmospheric flows, but which may require further refining, hence beyond the scope of this study. The presence of high-entropy air is additionally visible as part of the monsoon depression and orographic convection over the Indian region. 


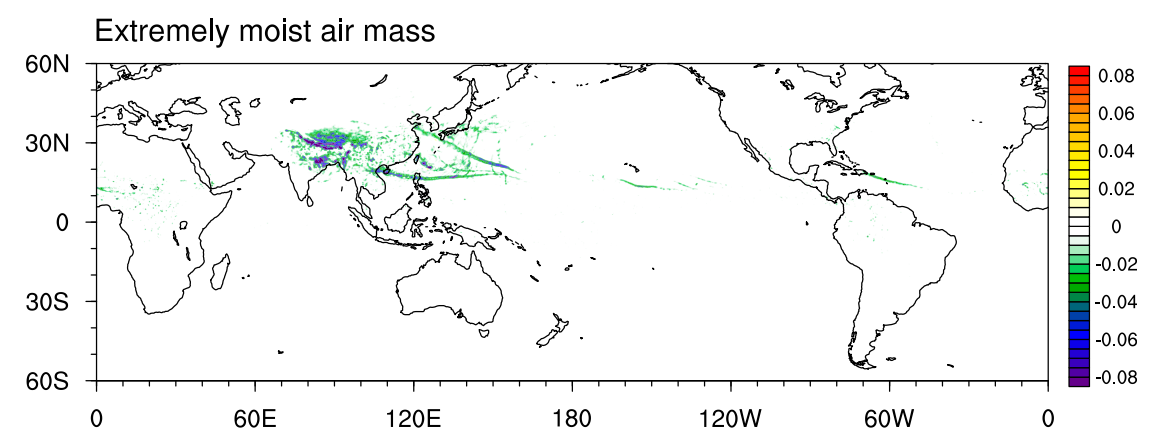

FIG. 7. Isentropic vertical velocity $\left(\omega_{\theta_{e, Z}}\right)$ at $500 \mathrm{hPa}\left(\mathrm{Pa} \mathrm{s}^{-1}\right)$ for extremely warm and moist range of equivalent potential temperature $\left(358<\theta_{e}<367 \mathrm{~K}\right)$ shown for a representative month (August 1982) from the simulation.

\section{Properties of air masses associated with different monsoon phases}

The Indian monsoon has large variations on intraseasonal and interannual time scales with precise delineating features in rainfall and circulation. Here we endeavor to utilize the isentropic diagnostics to identify the air mass characteristics associated with seasonal and subseasonal variability of the monsoon.

\section{a. Interannual variability of monsoon}

Although the summer monsoon over India arises routinely during the months of JJAS, the year-to-year fluctuation in the seasonal mean rainfall is quite considerable, with significant impacts on the Indian economy. This seasonal variability of monsoons is nonperiodic and may result from the inherent atmospheric dynamics (Krishnamurthy and Shukla 2000) that emerge due to nearby or external drivers (Krishnamurthy and Kinter 2003). The seasonal anomalies of composites of years with contrasting rainfall (wet/dry) are selected following the India Meteorological Department criteria, that is, the years more than $10 \%$ above or below the seasonal mean over the Indian region for the JJAS seasons (Figs. 8a,b). Among the wet years, most of the land regions of India encounter an overabundance of precipitation, particularly over the central and western coastal belt, while an opposite pattern with limited rainfall is experienced in the dry years, which is well comparable with observed datasets (figure not shown).

The anomalies of isentropic thickness and mass transport for composites of wet and dry monsoon years for the JJAS season are shown in Fig. 9. This confirms the strong interannual fluctuation in isentropic thickness and mass transport following the wet and dry years. The strong positive anomalies of the Asian monsoon air mass $\left(343<\theta_{e}<357 \mathrm{~K}\right)$ and mass transport depict the strength of the warm, moist air mass associated with enhanced precipitation during the wet years (Fig. 9d). The relative absence of a subtropical dry air mass $(318<$ $\theta_{e}<332 \mathrm{~K}$ ) is apparent over the monsoon domain, and the abundance of the tropical moist air mass $\left(333<\theta_{e}<\right.$ $342 \mathrm{~K})$ can be observed over the Arabian Sea and southern Arabian peninsula, with the mass transport extending to the Bay of Bengal (Figs. 9b,c). However, during the dry years, low isentropic thickness substantially supports the subdued convection over central India, with a weak mass transport represented by the anomalous anticyclonic circulation associated with the Asian monsoon air mass (Fig. 9i; $343<\theta_{e}<357 \mathrm{~K}$ ). The tropical moist air mass (Fig. 9h) is mostly dominant over the equatorial Indian Ocean, south central Arabian Sea and over the monsoon trough zone during the dry years. The relative abundance of the tropical moist air mass with $\theta_{e}<342 \mathrm{~K}$ over the monsoon trough region (Fig. 9h) instead of the moist Asian monsoon air mass, which would have induced deep convection there, is an indirect representation of the weak convective activity during the dry years.

The anomalous thickness and circulation pattern in the $\theta_{e}<332 \mathrm{~K}$ range demonstrate the presence of a cold and dry subtropical air mass over the monsoon region during the dry years (Fig. 9g). The subtropical air mass is higher over inland central India, the northwestern flanks of the Indo-Pakistan region and the northern Arabian Sea. This is a strong confirmation of previous investigations that addressed the midlatitude interactions during dry seasons in the Indian summer monsoon (Krishnan et al. 2009). However, the isentropic investigation provides clear proof of these arguments in a pragmatic way. This cold, dry air advected from the subtropics can enhance anomalous cooling and eventually act as a robust dynamical factor that can diminish the convection over the north Indian plains (Krishnamurti et al. 2010). These internally forced droughts can be mostly connected with prolonged breaks that occur 
a) Wet

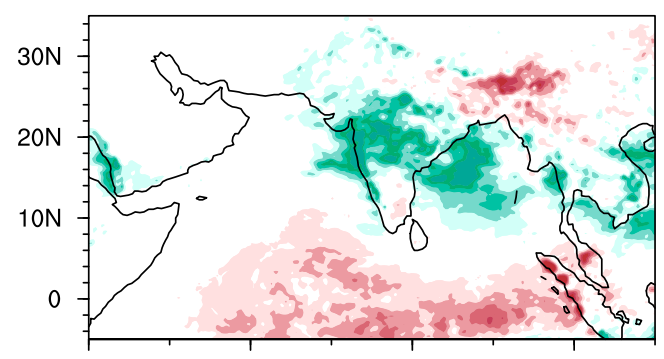

c) Active

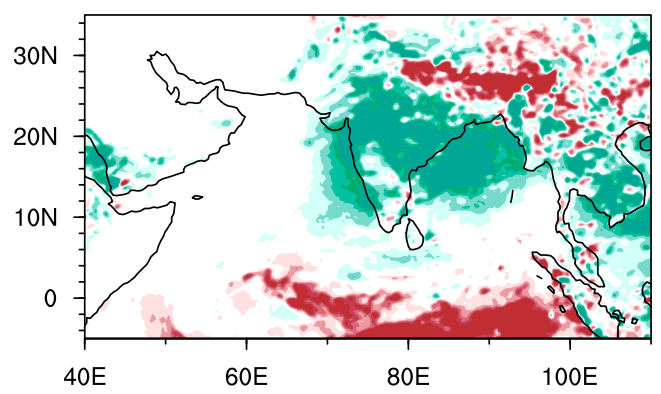

b) Dry

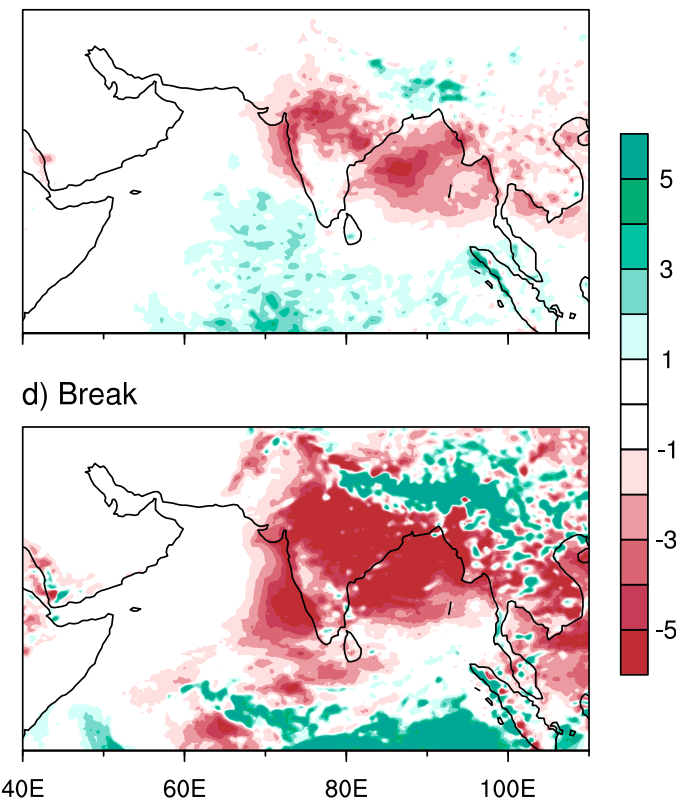

FIG. 8. Composites of the seasonal (JJAS) monsoon rainfall anomalies $\left(\mathrm{mm} \mathrm{day}^{-1}\right)$ for (a) wet years, (b) dry years, (c) active cases, and (d) break cases from the HiRAM simulation.

on subseasonal time scales (Krishnan et al. 2009). Interannual variations of Indian summer monsoon are partially emerging due to the intraseasonal variability (i.e., the active-break cycle; Goswami and Xavier 2005; Suhas et al. 2012) within the season. Hence, the dynamical feedback of extratropical interaction with monsoon convection on a subseasonal scale also influences the seasonal mean, which is demonstrated in the following section.

\section{b. Dry air incursion during break phases}

Active and break monsoon phases are convectively coupled moist process on a subseasonal time scale characterized by enhanced and subdued rainfall, respectively, over the Indo-Gangetic Plain (Rajeevan et al. 2010; Joseph and Sabin 2008). The incursion of dry air toward central India and the Arabian Sea during the break phase is reported using back trajectories by Krishnamurti et al. (2010). Krishnan et al. (2009) observed the presence of the southward-penetrating midlatitude troughs, which can act as a blocking high and promote the advection of dry extratropical air toward the monsoon region. This dry air inhibits the vertical growth of deep convection over central India and adjoining plains (Sabin et al. 2013). Using the isentropic diagnostics, we demonstrated the existence of dry midlatitude air during the break phase of the monsoon. Here, we defined the active phase as when the normalized rainfall anomaly over the core monsoon zone exceeds +1.0 and the break phase as when it is less than -1.0 for at least three consecutive days, as followed by Rajeevan et al. (2010) (Figs. 8c,d). Figure 10 is the composite mean isentropic thickness and mass transport for the break phase (right panel) and active phase (left panel) from the simulation. The subtropical dry air mass in the moist ventilation range $318<\theta_{e}<332 \mathrm{~K}$ is clearly depicted, with cold, dry midlatitude or desert air present over the Arabian Sea and extending eastward toward the Indian landmass (Fig. 10g). The intrusion of dry air toward the land occurs for the most part through the gaps in the Hindu Kush range and over the Arabian Sea from the subtropics and Arabian Desert. The descending air from the upper troposphere or from the Arabian Desert is extremely dry, which can either limit the moisture content of the low-level oceanic inflow or reduce the parcel buoyancy through radiative thermal inversion. We verified the long break phase (breaks exceeding 7 days) from the model (figure not shown), during which the subtropical dry air intrusion steadily increased and expanded more toward the Arabian Sea and Indian landmass compared to the composite of all breaks shown in Fig. 10g. However, during the active phase, the dry air recedes from the vicinity of the monsoon domain and is confined over the arid desert region (Fig. 10b).

The strong persistence of the tropical moist air mass is clearly visible across the low-level jet over the Arabian Sea and southern Bay of Bengal, which is a clear 
Wet

a) Extratropical air mass

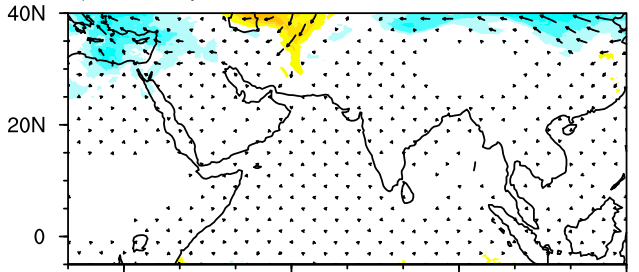

b) Subtropical dry air mass

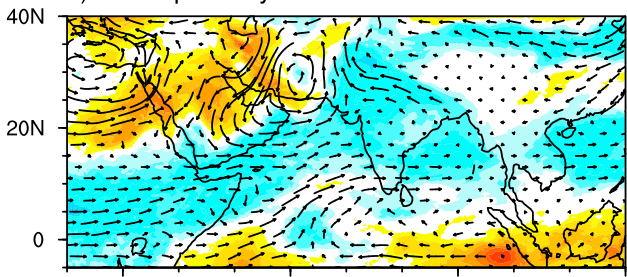

c) Tropical moist air mass

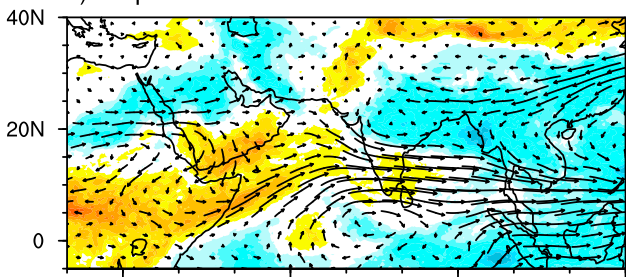

d) Asian monsoon air mass

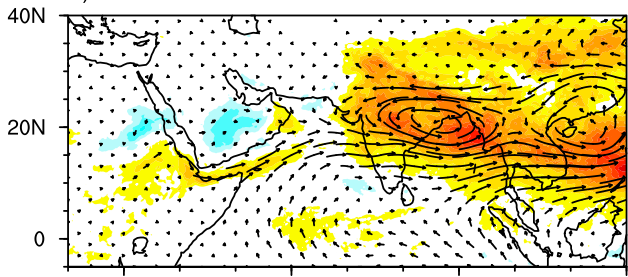

e) Extremely moist air mass

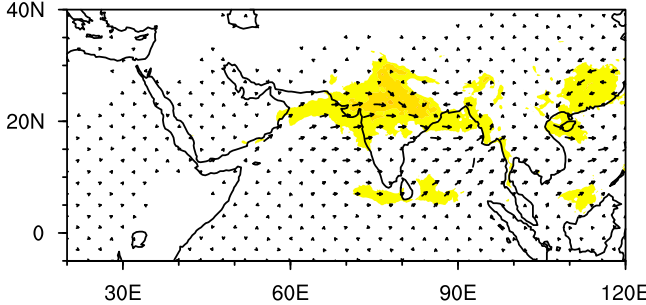

Dry

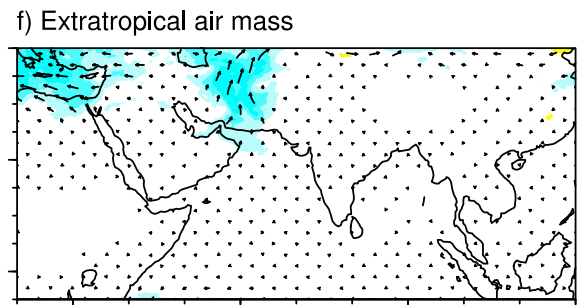

g) Subtropical dry air mass

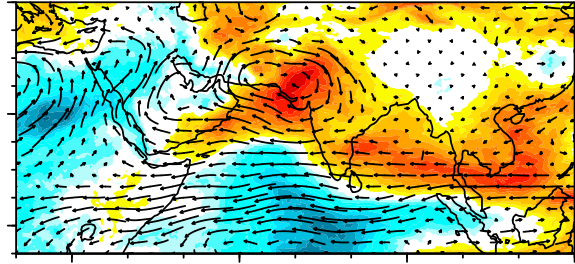

h) Tropical moist air mass

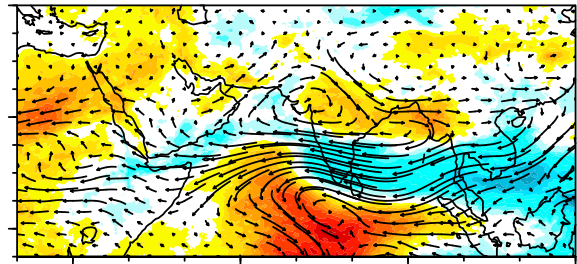

i) Asian monsoon air mass

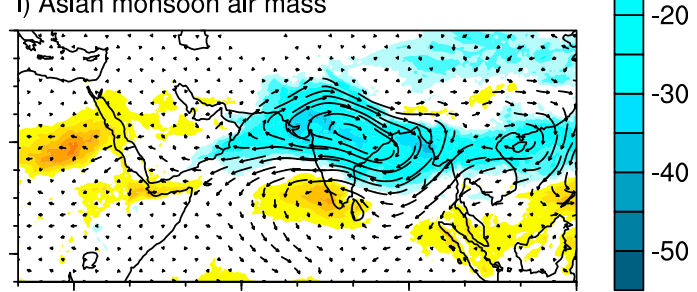

j) Extremely moist air mass

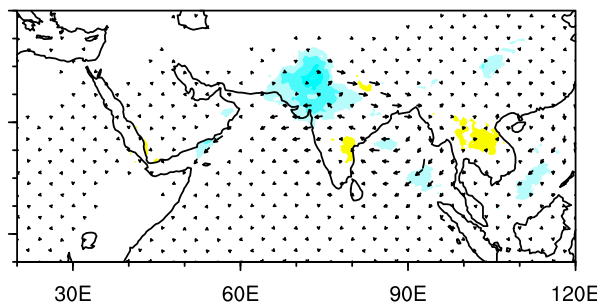

FIG. 9. Anomalies of the isentropic thickness (shading) in hectopascals and mass transport (arrows) for the different moist ventilation range of the tropical atmosphere in the lower troposphere (below $500 \mathrm{hPa}$ ) for composites of (left) wet and (right) dry years. Different moist ventilation ranges are as highlighted in Fig. 3.

manifestation of the cross-equatorial south westerly flow transporting moisture toward the Indian subcontinent (Fig. 10c). However, during break phases, this pattern is restricted to the areas over southeast India and adjacent Bay of Bengal, without the cross-equatorial counterpart delineating the reduced moisture supply. The maximum convection collocates with the warm and moist Asian monsoon air mass, which produces a large cyclonic circulation over a vast region covering the Indo-
Gangetic Plain and nearby oceans (Fig. 10d). The intense latent heating in the conditionally unstable tropical atmosphere will thermodynamically enhance the low pressure area associated with the monsoon trough, which further attracts moisture; both grow through a positive feedback process (Joseph and Sijikumar 2004). The extremely moist air mass $\left(358<\theta_{e}<367 \mathrm{~K}\right)$ confirms the intensity of deep convection during the active phase of the monsoon (Fig. 10e). During the break phase, the 


\section{Active}

a) Extratropical air mass

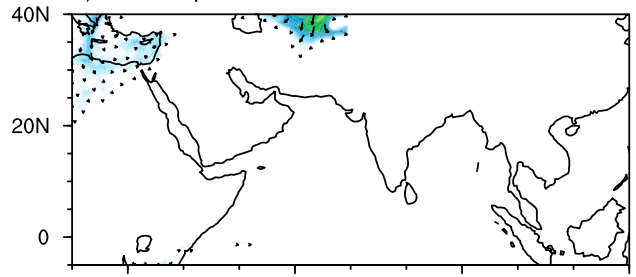

b) Subtropical dry air mass

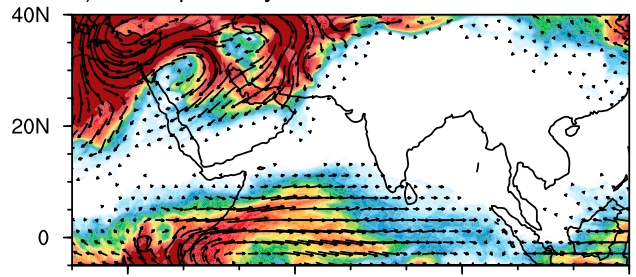

c) Tropical moist air mass

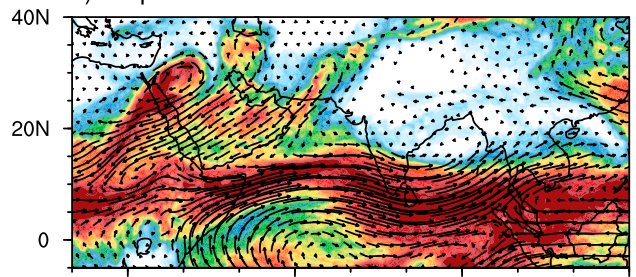

d) Asian monsoon air mass

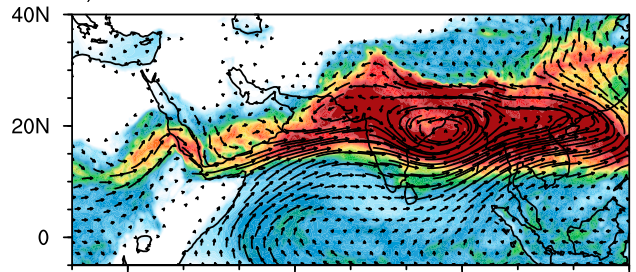

e) Extremely moist air mass

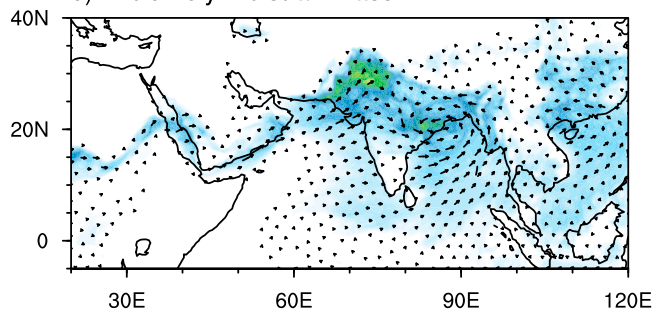

Break

f) Extratropical air mass

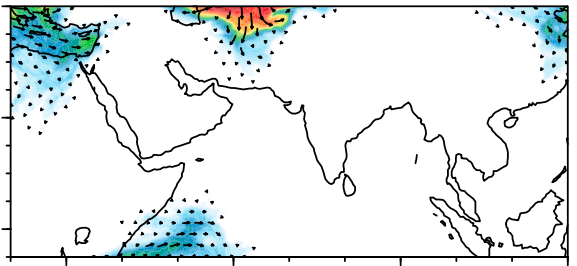

g) Subtropical dry air mass

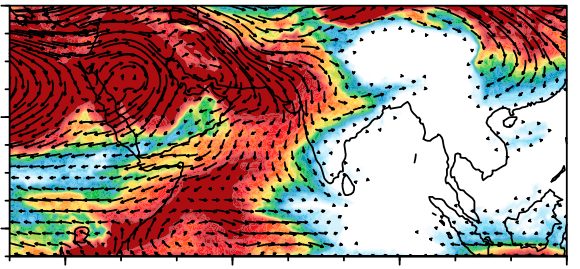

h) Tropical moist air mass

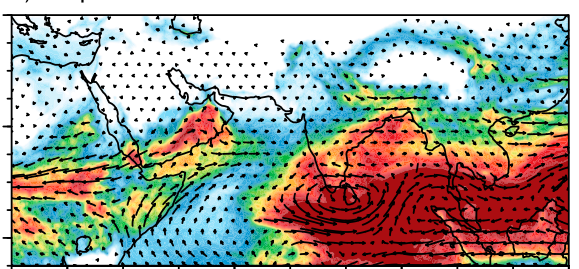

i) Asian monsoon air mass

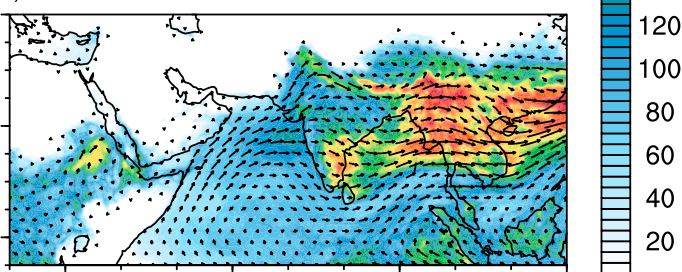

j) Extremely moist air mass

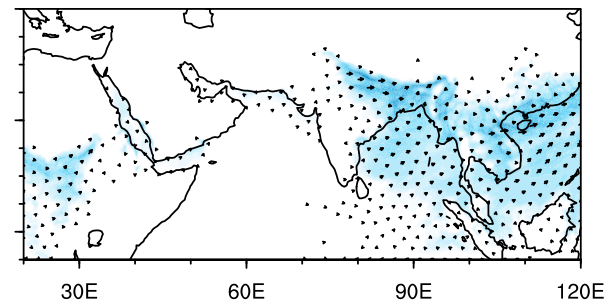

FIG. 10. As in Fig. 9, but for the (left) active and (right) break phases of the monsoon. Shown are maps depicting the composite mean pattern instead of the anomaly.

feeble mass transport and exceptional reduction in isentropic thickness associated with the Asian monsoon air mass are clear manifestations of the weak westerly flow and reduced convective activity over the monsoon trough (Fig. 10i). The extremely moist air mass with $\theta_{e}>$ $358 \mathrm{~K}$ occurs mainly over the Himalayan foothills, which is one of the classical features of the break phase of the monsoon (Fig. 10j), as discussed by many studies (Ramamurthy et al. 1976; Joseph and Sabin 2008; Rajeevan et al. 2010; Krishnamurthy and Ajayamohan 2010).

\section{Summary and discussion}

Using isentropic diagnostics, we have presented a thermodynamic perspective for the South Asian summer monsoon. We have shown that the meridional circulation in isentropic coordinates (Held and Schneider 1999; Pauluis et al. 2008, 2010; Pauluis and Mrowiec 2013) can be applied to explore the South Asian summer monsoon using the horizontal and vertical discretization of moist processes. Isentropic averaging is a useful tool to 
retrieve convective mass transport, which has the potential to address various thermodynamic properties of convective motion (Pauluis and Mrowiec 2013; Chen et al. 2018). This method is extended to depict the vertical ascent and descent associated with the boreal monsoon by reconstruction of the thermodynamic transformations that various air parcels undergo as they are being transported by the monsoon systems. This information is utilized to approximate the thermodynamic evolution of air parcels associated with organized monsoon convection.

The moist convection associated with the South Asian monsoon can be characterized through its complex dynamic and thermodynamic interactions. The lateral mass transport of air was identified with respect to both the potential temperature and equivalent potential temperature. The meridional mass flux on surfaces of constant dry and moist potential temperature decomposition were used to identify thermodynamically distinct mass flux movements over the monsoon domain. The results presented here demonstrate the properties of the various air masses, such as the outflow of the upper troposphere, the lower-layer inflow, and dry air intrusion from the midlatitudes.

Chen et al. (2018) quantified atmospheric overturning by computing mass transport in pressure and equivalent potential temperature coordinates following Pauluis and Mrowiec (2013). They documented monsoonal overturning into large-scale ascent over the Indian monsoon domain, the regional-scale overturning associated with synoptic systems, and the convective scale overturning. They noted that the majority of upward mass transport occurs in the lower level of the convective scale, while the regional scale component plays an important role in deepening the monsoonal overturning, with a maximum ascent over the midtroposphere. Though useful, this strategy is not sufficient to portray the spatial characteristics of air mass related to the Asian summer monsoon. The spatial characteristics of air parcels that we demonstrated through this study, including the isentropic thickness, mass transport, and vertical velocity of each moist ventilation range of the atmospheric column, fulfill the primary aim of providing a thermodynamic perspective for global monsoonal circulations. We have identified a thermodynamic pathway that describes the synchronous response of precipitation, its intensity, and the export of mass and energy toward and away from the monsoon region.

The analysis of various moist ventilation ranges clearly demonstrates the origin of the low-level flow, its intensification, and organization over the monsoon region. For a strong monsoon, it is necessary to have lowlevel moisture convergence, which generates strong upward motion. Cross-equatorial flow in the lower troposphere positively feeds moisture, which in turn enhances the organized convection over the monsoon region (Webster et al. 1998; Meehl 1987; Pearce and Mohanthy 1984; Joseph and Sabin 2008; Boos and Emanuel 2009). The air parcel rises adiabatically and eventually reaches saturation associated with the significant amounts of moisture availability. Since we quantified the horizontal mass transport in terms of equivalent potential temperature by separating between the lower (below $500 \mathrm{hPa}$ ) and upper (above $500 \mathrm{hPa}$ ) layers, the summer monsoon system can be simply demonstrated here with the Asian monsoon air mass in the moist ventilation range of $343<\theta_{e}<357 \mathrm{~K}$ (Fig. 11) as follows:

- Very warm, moist low-level Asian monsoon air mass associated with intense westerly flow is confined over the head of the Bay of Bengal and peninsular India, which produces strong low-level cyclonic vorticity over the monsoon trough and leads to intense precipitation. This technique makes it possible to identify and trace the transport of air parcels over long distances and assess the impacts of diabatic processes.

- The strong vertical ascent in the moist ventilation range of $343<\theta_{e}<357 \mathrm{~K}$ is a simple manifestation of the intense deep convection over the Bay of Bengal and Indo-Gangetic Plain. This provides us with a clear representation of the regions of convective motion with respect to the thermodynamic properties of the respective air mass.

- The upper-tropospheric structure (above $500 \mathrm{hPa}$ ) mainly reveals the anticyclonic circulation over the Tibetan Plateau and the thermodynamic centers of heating associated with the outflow of the Asian summer monsoon at high potential temperature.

Thus, we can infer the Asian monsoon system as an inflow of low-level warm and moist air compensated by a high equivalent potential temperature outflow in the upper troposphere. This technique makes it possible to understand the magnitude of unusually high equivalent potential temperature ascending over the monsoon region, which is the main reason for the global lifting of the tropopause during the northern summer. In addition to this, we were able to clearly show the dynamism of shielding the Asian monsoon region from extratropical and subtropical dry air. The analysis identifies the extremely warm and moist air mass depicting the presence of intense deep convection associated with the typhoons over the west Pacific, monsoon depression, and deep orographic convection. Thus, this method can be even extended to track tropical storms and low-pressure systems. The corresponding analysis of isentropic vertical velocity at $500 \mathrm{hPa}$ further confirms that the 


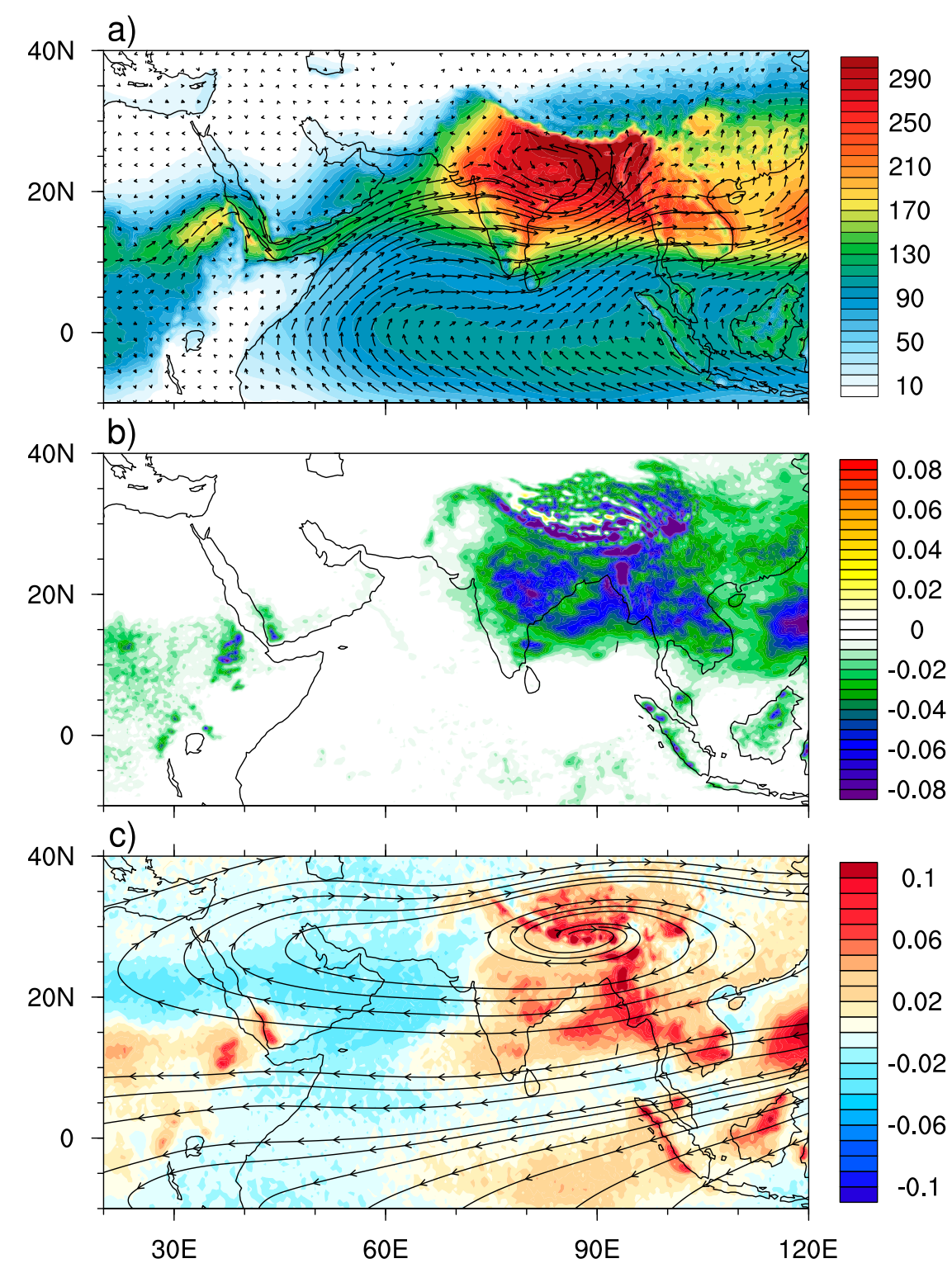

FIG. 11. The Asian monsoon system can be simply represented using the moist ventilation range $343<\theta_{e}<357 \mathrm{~K}$ : (a) low-level isentropic thickness (shading) and mass transport (arrows), (b) isentropic vertical velocity $\left(\omega_{\theta_{e, Z}}\right)$ at $500 \mathrm{hPa}$, and (c) divergence of upper-level mass flux (shading) and mass transport (streamline).

strong upward velocity is well collocated with the precipitation maxima over the monsoon region and shows the distinct difference between the tropical moist air mass and the Asian monsoon air mass. In addition to this, we could clearly show the transport of moisture toward the land from cross-equatorial flow, which is combined with dry air from nearby deserts in addition to the warm, moist tropical air mass; over the ocean, however, this was confined to the equatorward transport of cold dry air and poleward transport of warm moist air. In a nutshell, analyzing circulation on an isentropic framework offers a simple tool to connect mass and energy transport from a regional to a global perspective. A zonally averaged circulation simplifies the actual three-dimensional atmospheric flows, as evident from the analysis put forward to describe the monsoonal circulation. Combining these new isentropic diagnostics provides a novel approach to understand the thermodynamic and moist processes of the South Asian summer monsoon in an efficient way. 
Acknowledgments. TPS acknowledges the postdoctoral fellowship of the Center for Prototype Climate Modelling (CPCM), New York University (NYU). CPCM is funded by the Research Institute Grant of NYU, Abu Dhabi. OP acknowledges the support of the New York University Abu Dhabi Research Institute Grant. The HiRAM model is obtained from Geophysical Fluid Dynamics Laboratory, Princeton, New Jersey, and simulation performed at CPCM, NYU. The authors thank the three anonymous reviewers and the editor for their valuable comments which substantially improved this paper.

\section{REFERENCES}

Anderson, J. L., and Coauthors, 2004: The new GFDL global atmosphere and land model AM2-LM2: Evaluation with prescribed SST simulations. J. Climate, 17, 4641-4673, https://doi. org/10.1175/JCLI-3223.1.

Boos, W. R., and K. A. Emanuel, 2009: Annual intensification of the Somali jet in a quasi-equilibrium framework: Observational composites. Quart. J. Roy. Meteor. Soc., 135, 319-335, https:// doi.org/10.1002/qj.388.

_ - and Z. Kuang, 2010: Dominant control of the South Asian monsoon by orographic insulation versus plateau heating. Nature, 463, 218-222, https://doi.org/10.1038/nature08707.

- and - 2013: Sensitivity of the South Asian monsoon to elevated and non-elevated heating. Sci. Rep., 3, 1192, https:// doi.org/10.1038/srep01192.

Bretherton, C. S., J. R. McCaa, and H. Grenier, 2004: A new parameterization for shallow cumulus convection and its application to marine subtropical cloud-topped boundary layers. Part I: Description and 1D results. Mon. Wea. Rev., 132, 864-882, https://doi.org/10.1175/1520-0493(2004) 132<0864:ANPFSC $>2.0 . \mathrm{CO} ; 2$.

Brown, R. G., and C. Zhang, 1997: Variability of mid tropospheric moisture and its effect on cloud-top height distribution during TOGA COARE. J. Atmos. Sci., 54, 2760-2774, https://doi.org/ 10.1175/1520-0469(1997)054<2760:VOMMAI >2.0.CO;2.

Bunker, A. F., 1965: Interaction of the summer monsoon air with the Arabian Sea. Proc. Symp. on Meteorological Results of IIOE, Bombay, India, International Indian Ocean Expedition, 3-16.

Cadet, D., 1979: Meteorology of the Indian summer monsoon. Nature, 279, 761-767, https://doi.org/10.1038/279761a0.

Chen, X., O. M. Pauluis, L. R. Leung, and F. Zhang, 2018: Multiscale atmospheric overturning of the Indian summer monsoon as seen through isentropic analysis. J. Atmos. Sci., 75, 3011-3030, https://doi.org/10.1175/JAS-D-18-0068.1.

Chou, C., and J. D. Neelin, 2003: Mechanisms limiting the Northward extent of the northern summer monsoons over North America, Asia, and Africa. J. Climate, 16, 406-425, https://doi.org/10.1175/1520-0442(2003)016<0406:MLTNEO> 2.0.CO;2.

Choudhury, A. D., and R. Krishnan, 2011: Dynamical response of the South Asian monsoon trough to latent heating from stratiform and convective precipitation. J. Atmos. Sci., 68, 1347-1363, https://doi.org/10.1175/2011JAS3705.1.

Czaja, A., and J. Marshall, 2006: The partitioning of poleward heat transport between the atmosphere and ocean. J. Atmos. Sci., 63, 1498-1511, https://doi.org/10.1175/JAS3695.1.
Emanuel, K. A., 1994: Atmospheric Convection. Oxford University Press, 580 pp.

Fadnavis, S., and R. Chattopadhyay, 2017: Linkages of subtropical stratospheric intraseasonal intrusions with Indian summer monsoon deficit rainfall. J. Climate, 30, 5083-5095, https:// doi.org/10.1175/JCLI-D-16-0463.1.

Gadgil, S., 2003: The Indian monsoon and its variability. Annu. Rev. Earth Planet. Sci., 31, 429-467, https://doi.org/10.1146/ annurev.earth.31.100901.141251.

, 2018: The monsoon system: Land-sea breeze or the ITCZ? J. Earth Syst. Sci., 127, 1, https://doi.org/10.1007/s12040-0170916-x.

Goswami, B. N., and P. K. Xavier, 2005: Dynamics of "internal" interannual variability of Indian summer monsoon in a GCM. J. Geophys. Res., 110, D24104, https://doi.org/10.1029/ 2005JD006042.

Held, I. M., and T. Schneider, 1999: The surface branch of the zonally averaged mass transport circulation in the troposphere. J. Atmos. Sci., 56, 1688-1697, https://doi.org/10.1175/ 1520-0469(1999)056<1688:TSBOTZ>2.0.CO;2.

Huffman, G. J., and Coauthors, 2007: The TRMM Multisatellite precipitation analysis: Quasi-global, multiyear, combined-sensor precipitation estimates at fine scale. J. Hydrometeor., 8, 38-55, https://doi.org/10.1175/JHM560.1.

Johnson, D. R., 1989: The forcing and maintenance of global monsoonal circulations: An isentropic analysis. Adv. Geophys., 31, 43-316, https://doi.org/10.1016/S0065-2687(08)60053-9.

Joseph, P. V., and S. Sijikumar, 2004: Intraseasonal variability of the low-level jet stream of the Asian summer monsoon. J. Climate, 17, 1449-1458, https://doi.org/10.1175/15200442(2004)017<1449:IVOTLJ>2.0.CO;2.

— mechanism for the active break cycle of the Asian summer monsoon. Climate Dyn., 30, 553-566, https://doi.org/10.1007/ s00382-007-0305-2.

Krishnamurthy, V., and J. Shukla, 2000: Intraseasonal and interannual variability of rainfall over India. J. Climate, 13, 4366-4377, https://doi.org/10.1175/1520-0442(2000) $013<0001$ :IAIVOR $>2.0 . \mathrm{CO} ; 2$.

- and J. L. Kinter, 2003: The Indian monsoon and its relation to global climate variability. Global Climate: Current Research and Uncertainties in the Climate System, X. Rodó and F. A. Comín, Eds., Springer, 186-236.

— , and R. Ajayamohan, 2010: Composite structure of monsoon low pressure systems and its relation to Indian rainfall. J. Climate, 23, 4285-4305, https://doi.org/10.1175/2010JCLI2953.1.

Krishnamurti, T., A. Thomas, A. Simon, and V. Kumar, 2010: Desert air incursions, an overlooked aspect, for the dry spells of the Indian summer monsoon. J. Atmos. Sci., 67, 3423-3441, https://doi.org/10.1175/2010JAS3440.1.

Krishnan, R., V. Kumar, M. Sugi, and J. Yoshimura, 2009: Internal feedbacks from monsoon-midlatitude interactions during droughts in the Indian summer monsoon. J. Atmos. Sci., 66, 553-578, https://doi.org/10.1175/2008JAS2723.1.

Laliberté, F., J. Zika, L. Mudryk, P. J. Kushner, J. Kjellsson, and K. Döös, 2015: Constrained work output of the moist atmospheric heat engine in a warming climate. Science, 347, 540543, https://doi.org/10.1126/science.1257103.

Lin, P., D. Paynter, M. Yi, and V. Ramaswamy, 2017: Changes of the tropical tropopause layer under global warming. J. Climate, $\mathbf{3 0}$, 1245-1258, https://doi.org/10.1175/JCLI-D-16-0457.1.

Lin, S.-J., 2004: A vertically Lagrangian finite-volume dynamical core for global models. Mon. Wea. Rev., 132, 2293-2307, 
https://doi.org/10.1175/1520-0493(2004)132<2293:AVLFDC> 2.0.CO;2.

Mapes, B. E., and P. Zuidema, 1996: Radiative-dynamical consequences of dry tongues in the tropical troposphere. J. Atmos. Sci., 53, 620-638, https://doi.org/10.1175/15200469(1996) 053<0620:RDCODT > 2.0.CO;2.

Meehl, G. A., 1987: The annual cycle and interannual variability in the tropical Pacific and Indian Ocean regions. Mon. Wea. Rev., 115, 27-50, https://doi.org/10.1175/1520-0493(1987) $115<0027$ :TACAIV $>2.0 . \mathrm{CO} ; 2$.

Mrowiec, A. A., O. Pauluis, A. Fridlind, and A. Ackerman, 2015: Properties of a mesoscale convective system in the context of an isentropic analysis. J. Atmos. Sci., 72, 1945-1962, https:// doi.org/10.1175/JAS-D-14-0139.1.

— _ — , and F. Zhang, 2016: Isentropic analysis of a simulated hurricane. J. Atmos. Sci., 73, 1857-1870, https://doi.org/ 10.1175/JAS-D-15-0063.1.

Nie, J., W. R. Boos, and Z. Kuang, 2010: Observational evaluation of a convective quasi-equilibrium view of monsoons. J. Climate, 23, 4416-4428, https://doi.org/10.1175/2010JCLI3505.1.

Parker, D. J., P. Willetts, C. Birch, A. G. Turner, J. H. Marsham, C. M. Taylor, S. Kolusu, and G. M. Martin, 2016: The interaction of moist convection and mid-level dry air in the advance of the onset of the Indian monsoon. Quart. J. Roy. Meteor. Soc., 142, 2256-2272, https://doi.org/10.1002/qj.2815.

Pauluis, O. M., and A. A. Mrowiec, 2013: Isentropic analysis of convective motions. J. Atmos. Sci., 70, 3673-3688, https:// doi.org/10.1175/JAS-D-12-0205.1.

—, A. Czaja, and R. Korty, 2008: The global atmospheric circulation on moist isentropes. Science, 321, 1075-1078, https:// doi.org/10.1126/science.1159649.

,-- , and -2010 : The global atmospheric circulation in moist isentropic coordinates. J. Climate, 23, 3077-3093, https:// doi.org/10.1175/2009JCLI2789.1.

Pearce, R., and U. Mohanthy, 1984: Onsets of the Asian summer monsoon 1979-82. J. Atmos. Sci., 41, 1620-1639, https://doi.org/ 10.1175/1520-0469(1984)041<1620:OOTASM>2.0.CO;2.

Putman, W. M., and S.-J. Lin, 2007: Finite-volume transport on various cubed-sphere grids. J. Comput. Phys., 227, 55-78, https://doi.org/10.1016/j.jcp.2007.07.022.

Rajeevan, M., S. Gadgil, and J. Bhate, 2010: Active and break spells of the Indian summer monsoon. J. Earth Syst. Sci., 119, 229-247, https://doi.org/10.1007/s12040-010-0019-4.

Ramamurthy, K., R. Jambunathan, and D. Sikka, 1976: Moisture distribution and water vapour flux over the Arabian Sea during active and weak spells of southwest monsoon. Ind. J. Met Hydrol. Geophys, 27, 127-140.

Rienecker, M. M., and Coauthors, 2011: MERRA: NASA's ModernEra Retrospective Analysis for Research and Applications. J. Climate, 24, 3624-3648, https://doi.org/10.1175/JCLI-D11-00015.1.

Ronchi, C., R. Iacono, and P. S. Paolucci, 1996: The "cubed sphere:" A new method for the solution of partial differential equations in spherical geometry. J. Comput. Phys., 124, 93-114, https:// doi.org/10.1006/jcph.1996.0047.
Rossby, C.-G., and Coauthors, 1937: Isentropic analysis. Bull. Amer. Meteor. Soc., 18, 201-209, https://doi.org/10.1175/15200477-18.6-7.201.

Sabin, T. P., R. Krishnan, J. Ghattas, S. Denvil, J.-L. Dufresne, F. Hourdin, and T. Pascal, 2013: High resolution simulation of the South Asian monsoon using a variable resolution global climate model. Climate Dyn., 41, 173-194, https://doi.org/ 10.1007/s00382-012-1658-8.

Sandeep, S., R. Ajayamohan, W. R. Boos, T. P. Sabin, and V. Praveen, 2018: Decline and poleward shift in Indian summer monsoon synoptic activity in a warming climate. Proc. Natl. Acad. Sci. USA, 115, 2681-2686, https://doi.org/10.1073/ pnas.1709031115.

Shaw, T. A., 2014: On the role of planetary-scale waves in the abrupt seasonal transition of the Northern Hemisphere general circulation. J. Atmos. Sci., 71, 1724-1746, https://doi.org/ 10.1175/JAS-D-13-0137.1.

— , and O. Pauluis, 2012: Tropical and subtropical meridional latent heat transports by disturbances to the zonal mean and their role in the general circulation. J. Atmos. Sci., 69, 18721889, https://doi.org/10.1175/JAS-D-11-0236.1.

Sherwood, S., R. Roca, T. Weckwerth, and N. Andronova, 2010: Tropospheric water vapor, convection, and climate. Rev. Geophys., 48, RG2001, https://doi.org/10.1029/2009RG000301.

Suhas, E., J. M. Neena, and B. N. Goswami, 2012: Interannual variability of Indian summer monsoon arising from interactions between seasonal mean and intraseasonal oscillations. J. Atmos. Sci., 69, 1761-1774, https://doi.org/10.1175/JAS-D11-0211.1.

Townsend, R. D., and D. R. Johnson, 1985: A diagnostic study of the isentropic zonally averaged mass circulation during the first GARP global experiment. J. Atmos. Sci., 42, 1565-1579, https://doi.org/10.1175/1520-0469(1985)042<1565:ADSOTI> 2.0.CO;2.

Webster, P. J., V. O. Magana, T. Palmer, J. Shukla, R. Tomas, M. Yanai, and T. Yasunari, 1998: Monsoons: Processes, predictability, and the prospects for prediction. J. Geophys. Res., 103, 14 451-14 510, https://doi.org/10.1029/97JC02719.

Wu, Y., and O. Pauluis, 2013: Examination of isentropic circulation response to a doubling of carbon dioxide using statistical transformed Eulerian mean. J. Atmos. Sci., 70, 1649-1667, https://doi.org/10.1175/JAS-D-12-0235.1.

$\longrightarrow$, and - 2014: Midlatitude tropopause and low-level moisture. J. Atmos. Sci., 71, 1187-1200, https://doi.org/10.1175/ JAS-D-13-0154.1.

_ - J. Lu, and O. Pauluis, 2019: Weakening of upward mass but intensification of upward energy transport in a warming climate. Geophys. Res. Lett., 46, 1672-1680, https://doi.org/ 10.1029/2018GL081399.

Zhao, M., I. M. Held, S.-J. Lin, and G. A. Vecchi, 2009: Simulations of global hurricane climatology, interannual variability, and response to global warming using a $50-\mathrm{km}$ resolution GCM. J. Climate, 22, 6653-6678, https://doi.org/ 10.1175/2009JCLI3049.1. 